Article

\title{
A Case for a New Satellite Mission for Remote Sensing of Night Lights
}

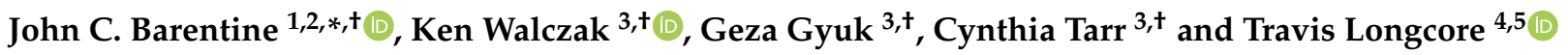 \\ 1 International Dark-Sky Association, 5049 E Broadway Blvd, Suite 105, Tucson, AZ 85711-3646, USA \\ 2 Consortium for Dark Sky Studies, University of Utah, 375 S 1530 E, RM 235 ARCH, \\ Salt Lake City, UT 84112-0730, USA \\ 3 Adler Planetarium, 1300 S Lake Shore Dr, Chicago, IL 60605, USA; kwalczak@adlerplanetarium.org (K.W.); \\ ggyuk@adlerplanetarium.org (G.G.); ctarr@adlerplanetarium.org (C.T.) \\ 4 UCLA Institute of the Environment and Sustainability, 300 La Kretz Hall, Los Angeles, CA 90095, USA; \\ longcore@ucla.edu \\ 5 The Urban Wildlands Group, P.O. Box 24020, Los Angeles, CA 90024, USA \\ * Correspondence: john@darksky.org; Tel.: +1-520-347-6363 \\ + These authors contributed equally to this work.
}

Citation: Barentine, J.C.; Walczak, K.; Gyuk, G.; Tarr, C.; Longcore, T. A Case for a New Satellite Mission for Remote Sensing of Night Lights. Remote Sens. 2021, 13, 2294. https:// doi.org/10.3390/rs13122294

Academic Editor: Xuecao Li

Received: 2 April 2021

Accepted: 7 June 2021

Published: 11 June 2021

Publisher's Note: MDPI stays neutral with regard to jurisdictional claims in published maps and institutional affiliations.

Copyright: (c) 2021 by the authors. Licensee MDPI, Basel, Switzerland. This article is an open access article distributed under the terms and conditions of the Creative Commons Attribution (CC BY) license (https:/ / creativecommons.org/licenses/by/ $4.0 /)$.

\begin{abstract}
The physiology and behavior of most life at or near the Earth's surface has evolved over billions of years to be attuned with our planet's natural light-dark cycle of day and night. However, over a relatively short time span, humans have disrupted this natural cycle of illumination with the introduction and now widespread proliferation of artificial light at night (ALAN). Growing research in a broad range of fields, such as ecology, the environment, human health, public safety, economy, and society, increasingly shows that ALAN is taking a profound toll on our world. Much of our current understanding of light pollution comes from datasets generated by remote sensing, primarily from two missions, the Operational Linescan System (OLS) instrument of the now-declassified Defense Meteorological Satellite Program (DMSP) of the U.S. Department of Defense and its follow-on platform, the Day-Night Band (DNB) of the Visible Infrared Imaging Radiometer Suite (VIIRS) instrument on board the Suomi National Polar-Orbiting Partnership satellite. Although they have both proved invaluable for ALAN research, sensing of nighttime lights was not the primary design objective for either the DMSP-OLS or VIIRS-DNB instruments; thus, they have some critical limitations. Being broadband sensors, both the DMSP-OLS and VIIRS-DNB instruments suffer from a lack of spectral information. Additionally, their spatial resolutions are too low for many ALAN research applications, though the VIIRS-DNB instrument is much improved over the DMSP-OLS in this regard, as well as in terms of dynamic range and quantization. Further, the very late local time of VIIRS-DNB observations potentially misses the true picture of ALAN. We reviewed both current literature and guiding advice from ALAN experts, aggregated from a diverse range of disciplines and Science Goals, to derive recommendations for a mission to expand knowledge of ALAN in areas that are not adequately addressed with currently existing orbital missions. We propose a stand-alone mission focused on understanding light pollution and its effects on our planet. Here we review the science cases and the subsequent mission recommendations for NITESat (Nighttime Imaging of Terrestrial Environments Satellite), a dedicated ALAN observing mission.
\end{abstract}

Keywords: artificial light at night; nighttime lights; light pollution; remote sensing; space missions; NITESat

\section{Introduction}

At every moment, half of the Earth experiences night. Over countless millennia, every animal, ecosystem, human being, city and settlement has adapted to the night as half of a natural cycle of light and dark set by the rising and setting of the Sun. In only a little more than a century, however, humans have transformed the night with the advent of 
widespread artificial illumination. Both the lit area of the Earth and the overall emission of light at night have increased in recent years at a global average annual rate of two percent [1]. The effects of this profound change are only now beginning to be understood, but they are known to include threats to ecosystems [2], human health [3], climate, and the visibility of the night sky [4]. There is also significant interest in understanding the influence of outdoor lighting on nighttime public safety [5].

The study of light pollution and its impacts on the nighttime environment is a relatively young and rapidly maturing field. (Google Scholar hits on "light pollution" are up 66\% and Artificial Light at Night Research Literature Database (alandb.darksky.org, accessed on 2 April 2021) paper listings are up by $370 \%$ on an annualized basis since 2010.) Recent years have seen the launches of subject-specific conference series, the establishment of an academic center (the Consortium for Dark Sky Studies at the University of Utah) [6], and a dedicated journal for publication of peer-reviewed research [7]. Researchers in dark-sky studies have recently called for its professionalization [8] and even suggested a name for the field: "nyctology" [9].

Much of this boon in light pollution research has been due to the public availability of remotely sensed data of the Earth at night. Earth-observing satellites have been providing invaluable information about our world since the beginning of the Space Age in the late 1950s. Although daytime observations of the Earth are ubiquitous, observations of the Earth at night have only been available relatively recently. Though not without limitations, these observations of artificial light at night (ALAN) from orbit have played a pivotal role in advancing the field of light pollution research over the past three decades. Currently available global datasets of ALAN have become available primarily from two satellite missions: the Suomi National Polar-Orbiting Partnership, equipped with the Visible Infrared Imaging Radiometer Suite Day-Night Band (VIIRS-DNB) in operation since 2012 yi [10,11], and the Defense Meteorological Satellite Program's Operational Linescan System (DMSP-OLS), whose digitized data are available from 1992 through 2013. Data from these missions have provided insights into the ecology, human health, economic and environmental impacts - to name a few-of ALAN that other methods cannot provide.

The extent and quality of the available satellite data of the Earth at night, though valuable, are lacking in many respects for the full state of the understanding of the effect of ALAN on our world. A dedicated mission to observe the Earth at night, tailored to the needs of research, would provide wide-ranging benefits for the study of ALAN in its multitude of interrelated fields. Although there is still much to learn about the impacts of ALAN, studies have so far shown that there are serious and even potentially fatal impacts from light pollution. For instance, it has been well established that chronic exposure to ALAN (particularly blue light) tends to suppress nocturnal melatonin production in humans and other vertebrates [12], which may trigger some forms of cancer [13-16], and has deleterious ecological repercussions. Some species are being threatened with extinction, due to interference from ALAN with their normal feeding, migration, or reproductive behavior $[17,18]$. Excessive and poorly implemented lighting has societal costs both direct and indirect. Inefficiencies in lighting have economic consequences as they incur substantial expense to municipalities, may have negative repercussions for social well being, and have a broader environmental impact through the release of large quantities of greenhouse gases.

Due to the increasing encroachment and intensity of ALAN, burgeoning transition into (bluer) LED lighting, and the general lack of strong lighting policies, it is urgent and crucial to have a spectrally resolved dataset of ALAN to fill current research gaps, support and inspire further study, and aid and inform advocacy efforts to establish and enforce responsible lighting practices. The Nighttime Imaging of Terrestrial Environments Satellite (NITESat), achievable as a small-satellite $(<500 \mathrm{~kg})$ mission, is a concept designed to answer questions that cannot be addressed by current methods [19]. This paper outlines the Science Goals driving a proposed NITESat concept and describes the subsequent mission characteristics required to meet those goals. 


\section{Science Goals}

In regards to Earth observing, ALAN research may suffer from an ambiguity in how it maps to scientific priorities. Its goals are environmental, ecological, epidemiological, economic, and sociological, yet not each alone. This paper argues that this diversity is a strength of the case for this effort. ALAN research spans a wide range of disciplines, yet all are driven by the need for an improvement in our understanding of the impacts of anthropogenic light at night on our world. To properly design the NITESat mission, it is important to pinpoint specific Science Goals the mission should address-particularly those goals that are not addressed by presently available data—and would benefit the most from the data a dedicated orbital satellite or instrument can provide.

The NITESat concept addresses a number of the goals laid out by the National Academies of Sciences, Engineering and Medicine (NASEM) in their 2018 Thriving on Our Changing Planet: A Decadal Strategy for Earth Observation from Space [20]. These include the following "Most Important" Goals and subsequent Objectives defined by the NASEM:

- (E-1) What are the structure, function, and biodiversity of Earth's ecosystems, and how and why are they changing in time and space?

- (E-1a) Quantify the distribution of the functional traits, functional types, and composition of terrestrial and shallow aquatic vegetation and marine biomass, spatially and over time. (Very Important)

- $\quad$ (E-1c) Quantify the physiological dynamics of terrestrial and aquatic primary producers. (Most Important)

- (C-2) How can we reduce the uncertainty in the amount of future warming of the Earth as a function of fossil fuel emissions, improve our ability to predict local and regional climate response to natural and anthropogenic forcings, and reduce the uncertainty in global climate sensitivity that drives uncertainty in future economic impacts and mitigation/adaptation strategies?

- (S-4) What processes and interactions determine the rates of landscape change?

- (S-4a) Quantify global, decadal landscape change produced by abrupt events and by continuous reshaping of Earth's surface from surface processes, tectonics, and societal activity. (Most Important)

- $\quad$ (S4c) Quantify ecosystem response to and causes of landscape change. (Important)

It could be argued that the NITESat concept fulfills an additional goal laid out in the Decadal Strategy. Goal (W-5) asks, "What processes determine the spatiotemporal structure of important air pollutants and their concomitant adverse impact on human health, agriculture, and ecosystems?" Although ALAN is not, strictly speaking, defined as an air pollutant, its propagation and transmission through our atmosphere has adverse effects on human health and ecosystems. Limited evidence suggests a photochemical nexus between artificial light at night and certain air pollutants [21], and that besides obvious public health benefits, reducing air pollution can concomitantly reduce skyglow over cities. Furthermore, ALAN sources observed from orbit may be used as probes of atmospheric conditions along the line of sight using well-developed radiative transfer analysis techniques [22-24]. The same approach can similarly be used to predict local night sky brightness values using remote sensing of upward radiance [25].

The NASA Science Mission Directorate (SMD) outlines its goals driven by the NASEM Decadal Strategy in Science 2020-2024: A Vision for Scientific Excellence [26]. From a top-level perspective, the NITESat concept meets all the NASA and SMD visions and goals outlined in their report. As a publicly funded research effort, the NITESat concept also comports with priorities of NASA and the National Academies of Science, Engineering and Medicine. Beyond these broad goals, there are many specific lines of scientific inquiry in a variety of diverse fields of study that NITESat aims to address. 


\subsection{ALAN Research Areas in Need of Expanded Remote Sensing Data}

After an initial review of the landscape of light pollution research and feedback from scientists engaged in a range of fields of active ALAN study, a number of outstanding scientific questions have been identified. The following are specific scientific goals, grouped by field of study, the NITESat mission concept should address. These goals are intended to be used to establish a baseline for the design and engineering requirements of the satellite and its mission design.

\subsubsection{Ecology}

ALAN exposure is known to harm a vast array of species on Earth [27]. Organisms at or near the surface of the Earth experience natural illumination levels spanning nine orders of magnitude with the timing and duration of those exposures largely determined by the Sun and Moon. Some species rely on dim sources of natural light, such as starlight and moonlight, for orientation and navigation [28]. Many other organisms rely on an absence of light at night to survive and flourish. ALAN is therefore a novel challenge to biological systems that evolved over billions of years in the presence of only natural conditions of nocturnal illumination. ALAN is known to disrupt physiological processes that rely on the daily and seasonal rhythms of light cues, such as foraging behaviors [29-32], timing of emergence [33-36], reproduction [37-40], communication [41-43], and migration [38,44]. ALAN has been explored as one of the factors that can lead to the disruption and weakening of interdependent ecological systems and food webs.

Satellite remote sensing is the only practical means of measuring ALAN exposure in some of the world's most sensitive ecosystems, because direct sensing in those places is difficult or impossible. Ecological studies fall into a number of categories where remotely sensed data at higher spatial, dynamic, or spectral resolution than current sources are needed to support advances. However, remote sensing data alone are insufficient to address many ecology research topics. Rather, a range of information sources, including ground-based measurements, is needed to validate biologically relevant ALAN exposures. While upward radiance sensed from orbit may represent a proxy for the total light emissions from ground-based sources, the relationship between upward radiance and illuminance of surfaces on the ground remains poorly constrained. If the relationship is well understood in the future, we may obtain a more reliable calibration between upward radiance and biologically relevant ALAN.

For physiological responses, it is not often practical to collect individual-level light exposures that might influence endogenous rhythms, stress, or recovery. These responses depend heavily on spectral content of lights combined with their intensity and can only be collected across large areas effectively using remote sensing.

For individual organismal responses, estimates of local light sources are important to understand everything from local habitat to landscape-level movement patterns. For example, use of wildlife crossing structures is influenced by light levels and sufficiently high resolution to quantify such conditions without extensive field work are currently unavailable or prohibitively expensive. With sufficiently resolved spatial data, it is possible to predict wildlife use by "darkest path" connections across a landscape, creating testable hypotheses for movement ecology with spillover benefits for road safety in avoiding vehicle-wildlife collisions.

At the scale of ecological communities, significant insights remain to be gained about predator-prey relationships, pollinator-plant relationships, and other ecological interactions. For example, recent research has demonstrated the influence of light at night at a coarse scale on mountain lion predation on mule deer [45]. Because irradiance from ALAN can vary orders of magnitude within several hundred meters [46], higherresolution data are needed to sort the influence of ALAN on many existing datasets containing ecological information. For example, the National Park Service has an extensive species monitoring program, the data from which are ideally suited for queries on the effects of ALAN on species distribution, co-occurrence, and abundance. (See, e.g., 
https:/ /www.nps.gov/im/medn/terrestrial-amphibians-and-reptiles.htm (accessed on 2 April 2021), data from which could be used to test hypotheses presented by Perry and Fisher [47].)

Finally, at the scale of ecosystems, high-resolution remotely sensed data are the only way to incorporate effects of ALAN into large, ongoing studies of ecosystem function such as the Long Term Ecological Research Network [48] and the National Ecological Observatory Network (NEON) [49].

Some specific examples of the questions of the ecological impacts of ALAN in need of expanded data include:

EL1 How do "dark corridors" and "light barriers" affect the migration and roaming habits of nocturnal species in and around urban environments [50]?

EL2 How does the encroachment of light at night impact ecologically sensitive species and ecosystems?

EL3 To what degree does ALAN contribute to the decline in and diversity of insect and pollinator populations [51]?

EL4 How are the spectral and spatial distributions of ALAN correlated? Are there different spatial distributions of the effect of spectra on different species [52]?

EL5 How does the addition of strong "local" light sources affect surrounding fauna and flora populations?

EL6 What is the regional effect of urban light domes on the surrounding environment?

EL7 What are the effects of spectra on an ecosystem, for example, in the conversions from lower-frequency-dominant (HPS) to higher-frequency-rich (LED) lighting?

\subsubsection{Environment}

Wasted outdoor light at night is wasted energy. To the extent that humans remain strongly dependent on carbon fuels to generate electricity, the issue of light pollution is one of energy use and its influence on global climate change. Prior to the introduction of energy-efficient solid-state lighting (SSL), electricity used to power outdoor lighting accounted for about $1.5 \%$ of global power consumption [53-55]. In the United States alone, the U.S. Department of Energy estimates that 255 TWh of energy are expended annually for outdoor lighting (commercial, industrial, private, and municipal) [56] that equates to the emission of over $180 \mathrm{M}$ metric tons of $\mathrm{CO}_{2}$. Remote sensing of night lights is itself an invaluable tool for tracking energy consumption and efficiency as it relates to carbon emissions. As a proxy for electric power consumption, night lights are known to correlate positively on different spatial scales with $\mathrm{CO}_{2}$ emission in recent decades [57], although with the proliferation of renewable energy sources around the world, this correlation may not hold in the future.

Motivated by the potential cost-of-ownership savings through reduced energy consumption and "green" policies promoting sustainable practices, municipalities have rushed to convert public outdoor lighting systems from incumbent technologies such as highintensity discharge lighting to solid-state lighting (SSL). As prices of SSL products steadily declined through the 2010s and the capital payback time for new installations decreased, the adoption rate of the new technology has accelerated.

A key unknown in the environmental impact of new outdoor lighting technologies is whether they are yielding results in line with expectations concerning reduced electricity consumption and carbon emissions. Kyba et al. [1]. compared satellite remote sensing observations in 2012-2016 showing changes in the lit area and quantity of light detected from orbit to changes in gross domestic product (GDP) on a per-country basis during the same period. They found a strong correlation between the lighting metrics and GDP change that they conclude is best explained by elastic demand in the consumption of outdoor light at night, which was "inconsistent with the hypothesis of large reductions in global energy consumption for outdoor lighting because of the introduction of solid-state lighting."

This conclusion implies that the financial savings brought on by switching from earlier lighting technologies to energy-efficient SSL has largely been redirected into procuring 
and deploying new outdoor lighting products, eroding expected gains in both energy consumption and related carbon emission. If this is true, then claims concerning the purported environmental benefits of SSL may be, at best, overstated. It has been argued that this calls for a new definition of "efficiency" that considers primarily the total cost of light rather than simply its electricity cost [58]. However, the authors were unable to rule out other explanations for the apparent correlation between global light emissions and GDP growth. Crucially, because of the blue-blindness of the VIIRS-DNB, the authors were unable to show conclusively that new lighting installed during the study period was in fact SSL and not merely an expansion of use of earlier technologies. More geographically granular data from improved spatial resolution and the addition of spectral information could answer this question definitively and better establish the existence of a putative causal relationship between energy efficiency, the cost of lighting, and the tendency of societies to consume it. Better data could help guide effective policy for the most efficient use of ALAN.

Some questions about the environmental impacts of ALAN unaddressed by present remote sensing data include:

EV1 What is the relationship between municipal lighting policy and $\mathrm{CO}_{2}$ emission as a proxy for environmental impact?

EV2 What is the inefficiency of outdoor lighting as the fraction of total light that is emitted at upward angles?

EV3 To what degree do spatially and temporally variable sources of ALAN such as oil and gas flares, fishing lights, mega greenhouses, etc., have an effect on the environment?

EV4 Is there an environmental benefit of LED transitions beyond energy efficiency (e.g., is there a rebound effect)?

EV5 What is an accurate level of gained energy efficiency (and thus $\mathrm{CO}_{2}$ emissions) realized in LED transitions?

\subsubsection{Economy}

Since the beginning of the civilian availability of satellite data with sufficient sensitivity to detect nighttime lights, remote sensing techniques have successfully exploited measurements of anthropogenic light emissions on the night side of Earth as an economic indicator and proxy for economic development. These include studies of the distribution of human settlement [59], indicators of economic development status [60], rates of regional and national electric power consumption [61-63], the presence of human conflict [64,65], disaster relief needs and progress [66,67], disease epidemiology [68,69], and even to assess the state of overall human well being [70]. Further applications include monitoring impacts of ground-based light sources on protected areas [71-73] and measuring various atmospheric characteristics [21,74,75], including greenhouse gas emissions [76].

At the same time, night lights observations from orbit indicate that the rate of growth of ALAN is often fastest in developing economies [1]. These countries often experience the technology "leapfrog" effect, in which they detour around the progressive adoption of succeeding technologies and proceed directly to what is considered current in more developed economies. Coupled with the arrival of inexpensive solid-state outdoor lighting on the global market, the rapid rise of new light may well presage the same problems with light pollution that have already prompted other countries to take action against it. A proper understanding of the lighting environment coupled with the proper quality of remotely sensed data can help in the development of effective and economically sound lighting policies.

Some of the pertinent questions related to the economic effects of light pollution include:

EO1 What is the economic impact of inefficiencies in light at night on communities and municipalities?

EO2 What is the economic cost of inefficient lighting in developing countries?

EO3 What are the best practices in the design of lighting policy to ensure a balance of results versus costs? 
EO4 To what degree does socioeconomic status correlate to ALAN exposure/environment?

EO5 What are the broad impacts of rural electrification programs on local well-being and sustainability?

EO6 What is the best balance of economic gain versus community costs of the lighting practices of production-scale greenhouses?

EO7 What are the best practices for communities intending to adopt LED lighting infrastructures?

\subsubsection{Policy and Society}

Remote sensing of night lights can contribute positively to the evaluation of lighting policies once implemented so that their framers may understand those policies' efficacy. Public policies and similar kinds of regulations aim to control outdoor lighting in order to reduce light pollution impact, among other reasons, but efficacy is usually measured on the micro level; for example, a question of this nature that might be answered on a highly local level is whether in the wake of new policy implementation, complaints about light trespass begin to ebb. However, more complex questions about light emissions reductions, environmental effects, and energy usage are difficult to answer with only micro-level data. In fact, light usage is often much easier to map and measure at regional scale through satellite imagery than by using any other method. Results of these measurements can be used to better evaluate lighting policies and provide feedback to decision makers on whether policies are cast in the right ways to achieve the desired results.

The most extensive study to date on the efficacy of public lighting modernization was carried out in Tucson, Arizona, after its LED street lighting retrofit (2016-2017). The City of Tucson wanted to take advantage of energy savings from increased energy efficiency, in part to fund a smart control system that allows for active dimming of street lights while protecting the quality of the night sky over astronomical observatories in the region. During the municipal project, Tucson converted $\sim 19,500$ street lights from legacy high-pressure sodium (HPS) luminaires to modern, network-addressable, $3000 \mathrm{~K}$ white LED luminaires. The new lights are routinely dimmed to $90 \%$ of their full power output to prolong the product life in the field, especially given the typically hot weather conditions the city experiences that tend to reduce the efficiency of LED lighting. Each night, a subset of about 16,000 luminaires, or $83 \%$ of all luminaires in the system, are dimmed to $60 \%$ of full power at midnight and remain in that configuration until they are routinely extinguished $30 \mathrm{~min}$ after local sunrise.

At the same time, Tucson significantly reduced the total light emission of its street lighting system in the conversion by reducing the output of the individual luminaires. Eighty watt LED luminaires replaced the existing 400 watt HPS luminaires, bringing the light emission of the street lighting system down by a factor of almost two-thirds to 161 million lumens from the pre-retrofit condition of 481 million lumens. Illuminances at street level were decreased by a factor of four while remaining above the minimum safe thresholds recommended by standard-setting bodies such as the Illuminating Engineering Society. VIIRS-DNB imagery obtained before and after the conversion showed a $-7 \%$ change in the total upward-directed radiance from Tucson, even accounting for the relative insensitivity of the DNB to the spectral power distribution difference between the old and new lights [77]. This measurement compared well to a model prediction of $-10 \%$.

Satellite remote sensing was also used in conjunction with limited (but detailed) lighting inventory information to determine the fraction of total Tucson light emissions attributable specifically to street lighting before the LED conversion (56\%). In spring 2019, the City of Tucson conducted a test of several special dimming configurations in which the total light emission from the street lighting system changed by a known amount. VIIRSDNB data were used to determine that post-retrofit the street lighting system accounts for $\lesssim 16 \%$ of total city light emissions [78], which compares favorably to the value inferred from an analysis of sky brightness changes during the tests indicating that street lights contribute $\lesssim 14 \%$ of the observed brightness at the zenith [79]. Taken together, these studies 
show that in a city with well-designed streetlights, most of the light emissions and light pollution come from sources other than street lights, such as illuminated signs, building façades, or outdoor athletic fields.

A major shortcoming of these studies is the inability to spatially resolve lighting types (public vs. private), and the insensitivity of the VIIRS-DNB to the color change of lighting in the LED transition. With sufficient spatial resolution and spectral discrimination, we could more readily begin to distinguish street lighting from sources such as commercial, residential, signs, etc. versus merely aggregating emissions.

There are a number of other relevant questions that could be addressed by new and better satellite remote sensing of night lights, including:

P1 How do policies resulting in specific lighting interventions change the light output of municipalities/regions/countries?

P2 How does policy and implementation relate to changes in night sky quality as seen from the ground?

P3 Which policies or interventions most effectively address the issues caused by ALAN?

P4 Can remote sensing evaluations of city light emissions help direct resources or guide decisions by targeting the "worst offenders"?

P5 Are there broad cultural patterns in the use of ALAN?

P6 Are social or political influences at work in determining the spatiotemporal distribution of outdoor light at night that may be driving social inequality in cities?

\subsubsection{Public Safety}

Among the motivators of the excessive use of light at night is the popular belief that the use of outdoor lighting improves road and traffic safety and discourages or prevents the perpetration of both violent and property crimes. While under certain circumstances the careful application of outdoor lighting may improve nighttime safety, this belief is not conclusively grounded in peer-reviewed scientific evidence. Some studies find evidence for a positive correlation in which crime or road collisions decrease after application of lighting treatments [80,81], while others find either a negative correlation [82], none at all [83-85], or ambiguous results [86]. A few authors turn the question around and ask whether reducing outdoor lighting in areas prone to either crime or road collisions leads to poorer outcomes, finding little or no such evidence [87].

A significant limiting factor in drawing clear and unqualified conclusions about the interaction of outdoor lighting and crime and road safety is that carefully controlled studies involving both are notoriously difficult to design, conduct, and interpret. A field of study, Crime Prevention Through Environmental Design (CPTED), uses urban and architectural design and the management of built and natural environments to examine various means of reducing criminal perpetration. Outcomes in CPTED research are often constricted by a lack of contextual data across study areas and could be improved with the addition of high-quality, high-resolution observations of light at night. As a result, many of the claims about outdoor lighting and its impact on public safety—for better or worse-may be fundamentally wrong $[88,89]$.

Traffic safety studies, in particular, have mission capability needs tuned to the parameters of roadways, such as high spatial resolution in order to distinguish between traffic lanes on roads with typical lane widths on the order of four meters. The frequency and timing of overpasses are also important to account for traffic volumes that may change significantly during the course of a night. At the same time, traffic studies published to date suggest that existing capabilities in terms of radiance and spectral sensitivity are sufficient to address many open questions.

Some of the outstanding questions related to crime and safety in relation to ALAN include:

S1 Does an increase in street lighting correlate to increase in traffic safety?

S2 Does an increase in outdoor lighting correlate to an improvement in public safety and incidences of crime?

S3 How does the design of the lit environment at night affect crime in urban environments? 
S4 Is there a correlation between the level of environmental outdoor lighting and nighttime crime and at what level those are benefits optimized?

\subsubsection{Human Health}

The causal relationship between ALAN exposure and human health and well being is a subject far from a clear understanding. Despite the unsettled nature of the science, there are clear indications that ALAN has deleterious effects on humans. These effects appear to stem largely from the ability of short-wavelength light to disrupt the circadian rhythm $[3,90]$ that governs everything from the timing of hormone secretion to the sleep-wake cycle. Exposure to ALAN at inappropriate times during this cycle delays or suppresses altogether the onset of the secretion of melatonin [91], a potent antioxidant known to interact with the immune system [92]. Melatonin is suppressed at very low light intensities, as little as 6 lux in sensitive humans [12], although a large range in human sensitivity to this effect has been observed [93]. The long-term health impacts of ALAN exposure are presently unknown, but it is suspected that chronic exposure to even dim ALAN has cumulative effects comparable to those from higher illuminances [94]. Some of the direct and downstream health impacts of exposure to ALAN may include stress, obesity, incidence of certain cancers, and illnesses related to sleep deprivation.

A number of studies have been performed attempting to correlate nighttime satellite data to observed health outcomes. Many of these studies admit that causal links between remote data and health indications are tenuous. Improved data may help to clarify this ambiguity and help to reduce confounding environmental factors in epidemiological research In conjunction and in support with other methods, it can help clarify the understanding of exposure to ALAN and subsequent health outcomes.

Some of the outstanding questions related to human health and safety in relation to ALAN include:

H1 Does an increased use of higher-frequency (bluer) outdoor lighting in an environment correlate to negative health of subjects in that environment?

H2 Are levels of outdoor ALAN correlated with an increase in human pathologies or diseases?

H3 Does ALAN influence the territorial stability of animals known as vectors of novel human diseases?

H4 Does outdoor light pollution affect host-pathogen interactions/disease dynamics [95]?

H5 Does ALAN affect air pollutants through modification of photo-sensitive chemical pathways leading to creation or destruction of specific molecular species?

\subsubsection{Characterization}

An important way in which remote sensing of night lights can contribute fundamentally to our understanding of the environmental pressures exerted by ALAN is through what is broadly referred to as the "characterization" of night lights. This method uses upward-directed radiance detected from orbit as an indication of human settlement patterns and as a proxy for electrical power consumption, economic activity, and more. Remote sensing enables the spatial and temporal determination of ALAN emission over vast swaths of territory in which it is otherwise impractical to obtain via detailed inventories of outdoor lighting stock or ground based observations alone. The applications of remote sensing characterization of night lights are varied, ranging from the assessment of the relative contributions of public and private lighting for the purpose of land use planning $[78,79]$ and modeling the extent of urban light emission impacts on surrounding environments, to evaluating the efficacy of dark-sky conservation policies and programs [73].

Three elements of characterization interact to provide information on the nature and impacts of ALAN: modeling, ground-based measurements of night sky brightness, and remote sensing of night lights. The overall system traces the path of artificial light from its emission on the ground to its flight through the atmosphere and its eventual detection either from space or by ground-based observers after one or more scattering events. Satellite 
remote sensing in particular offers a unique perspective on the problem: it sees the light that escapes the atmosphere completely, which may or may not involve interactions with molecules and aerosols on the way out. In many parts of the world, it provides the only ALAN characterization we have. We can infer much more from these observations than we could ever hope to get from putting night sky brightness monitors in very remote places.

The most extensive night lights dataset obtained through orbital remote sensing was published in 2016 and covers the window of time from2012 to 2015 [96]. This "New World Atlas of Artificial Night Sky Brightness" further offered some amount of temporal resolution during the study period, revealing trends in global light emissions on various spatial scales [1]. Further analysis of this dataset enabled drawing conclusions about ALAN use with progressively finer granularity [97]. Global radiance data are served online to the public through an interactive map, (https:/ / www.lightpollutionmap.info/, accessed on 2 April 2021) and include tools for conducting simple time-series analyses (https:/ /lighttrends.lightpollutionmap.info/, accessed on 2 April 2021.) The availability of these satellite remote sensing observations has revolutionized the study of night lights from low Earth orbit.

An optimized system for remotely sensing night lights from orbit would provide more than just information on the geographic distribution of ALAN and broadband radiance measurements. In order to cater to the needs of radiative-transfer modelers, who require a complex range of information, ideal data would include information on the spectral power distribution and angular emission functions of sources, the spectral reflectance of the ground, provide multispectral information, have a high dynamic range, and at best provide multiangular observations.

There are many open questions relating to ALAN characterization that a new mission can help answer, such as:

C1 What is the quantity of the world lighting inventory that has transitioned to LED lighting, and to what extent is that transition dominated by blue-rich lighting?

C2 How well do current radiative transfer models describe and define the extent of the impact of light pollution?

C3 To what degree do seasonal changes (tree canopies, snow cover, etc.) affect the impact of ALAN?

C4 How fast is ALAN growing? How is this growth spatially and socially distributed? Is the apparent rate of growth greater as seen in particular optical passbands?

C5 Are there particular classes of light sources that contribute greater amounts of excessive light at night above the local norm?

C6 What is the impact of transition to LEDs on upward emission and atmospheric scatter?

C7 What is the relationship between satellite-sensed upward radiance and typical human ALAN exposures in cities?

\section{Existing Orbital Data}

The first measurements of nighttime lights from satellite platforms was made in the early 1970s in a now-declassified U.S. Department of Defense project known as the Defense Meteorological Satellite Program (DMSP) [98]. Its Operational Linescan System (OLS) instrument uses a photomultiplier tube to detect nighttime lights to a nominal sensitivity limit of $0.5 \mathrm{nW} \mathrm{cm} \mathrm{cm}^{-2} \mathrm{sr}^{-1}$ across a broad (470-950 nm) optical passband at a spatial resolution of $3 \mathrm{~km}$ in its so-called "smooth" mode; a "fine" mode enables resolution to nearly half-kilometer scales. While images were originally captured on photographic film and sent to the ground for analysis, native digital OLS data have become available for the years 1992-2013. However, besides generally coarse spatial resolution, DMSP data have a number of limitations including six-bit quantization, relatively low dynamic range, and a lack of both spectral discrimination and on-board calibration $[99,100]$. Despite these issues, DMSP-OLS data were used in the late 1990s to create the first truly global atlas of light pollution [101], among other applications [102]. 
Many of the shortcomings of the DMSP-OLS data were addressed in the design of the VIIRS instrument, first launched aboard the Suomi National Polar Partnership satellite in 2011 [10]. VIIRS uses a "whiskbroom" scanning radiometer to collect imagery of Earth's clouds, atmosphere, oceans, and land surfaces at optical and near-infrared wavelengths $[10,11]$. The Day-Night Band channel provides $750 \mathrm{~m} \mathrm{px}^{-1}$ resolution that improved substantially on the DMSP-OLS instruments and achieves an even lower noise floor at $0.02 \mathrm{nW} \mathrm{cm}^{-2} \mathrm{sr}^{-1}$. The VIIRS-DNB photometric passband is comparable to DMSPOLS with sensitivity between 500 and $900 \mathrm{~nm}$. Possibly most important, the data from the VIIRS instrument is publicly available for research.

It is possible to achieve higher resolution and better spectral discrimination from Earth orbit. The best example to date is the RGB color imagery obtained by astronauts aboard the International Space Station [103-105]. These images often achieve spatial resolutions as small as $10 \mathrm{~m} \mathrm{px}^{-1}$, sufficient to begin identifying specific sources of outdoor light at night outside of dense urban areas; an example of such an image is shown in Figure 1.

However, most images from the ISS are not properly geotagged, and many often are seen at very oblique, unknown angles $[103,106]$. Furthermore, coverage is not very extensive and is unpredictable as it relies on the schedule of astronauts on board the ISS to produce images, an effort not typically scoped within their mission priorities. A citizen-science program to help identify the location of specific night targets has seen some success to date, (CitiesAtNight; http: / / citiesatnight.org/, accessed on 2 April 2021), though this effort is limited to the images that have been taken. Fortunately, all images taken by astronauts in this way are made publicly available.

In recent years, there have been efforts toward the development of small satellites or CubeSats to observe nighttime lights. The predecessor of nearly all these efforts is the 2007 "Nightsat" mission concept [107]. At that time, the DMSP-OLS instrument was the only orbital mission providing data for the study of global ALAN. The authors note in their paper eleven specific shortcomings of OLS observations and used a number of remote sensing experiments as proofs of concept for a satellite mission that could effectively address these issues. The Nightsat concept was the first attempt to lay out a thorough science case-and its requirements-for a dedicated night-lights-observing satellite mission.

In the intervening years the advent of smallsat technologies has ushered in a new class of potential nighttime observing missions. The tradeoff for the high spatial resolution and broadband spectral sensitivity of these missions is relatively short mission duration and/or limited coverage. These include the Chinese Luojia 1-01 (LJ1-01) [108,109], JL1-3B [110], and Jilin 1-07/08 missions, the Israeli EROS-B mission [111,112], and demonstrations on a number of Aerocube CubeSat missions from The Aerospace Corporation [113]. Small satellite and CubeSat missions have usually detected nighttime lights incidental to their primary mission of collecting remote sensing data of weather or land. Often, the data from these missions are not freely available to the public, are limited in coverage, or require expensive commercial requests for targeting, which severely limit their utility for research. While themselves not suited to addressing the science questions articulated here, the results of some of these missions demonstrate that the imaging technology to observe nighttime lights is mature, commercially viable, and capable of significantly advancing the science of ALAN. An example of this kind of imagery is shown in Figure 2. 


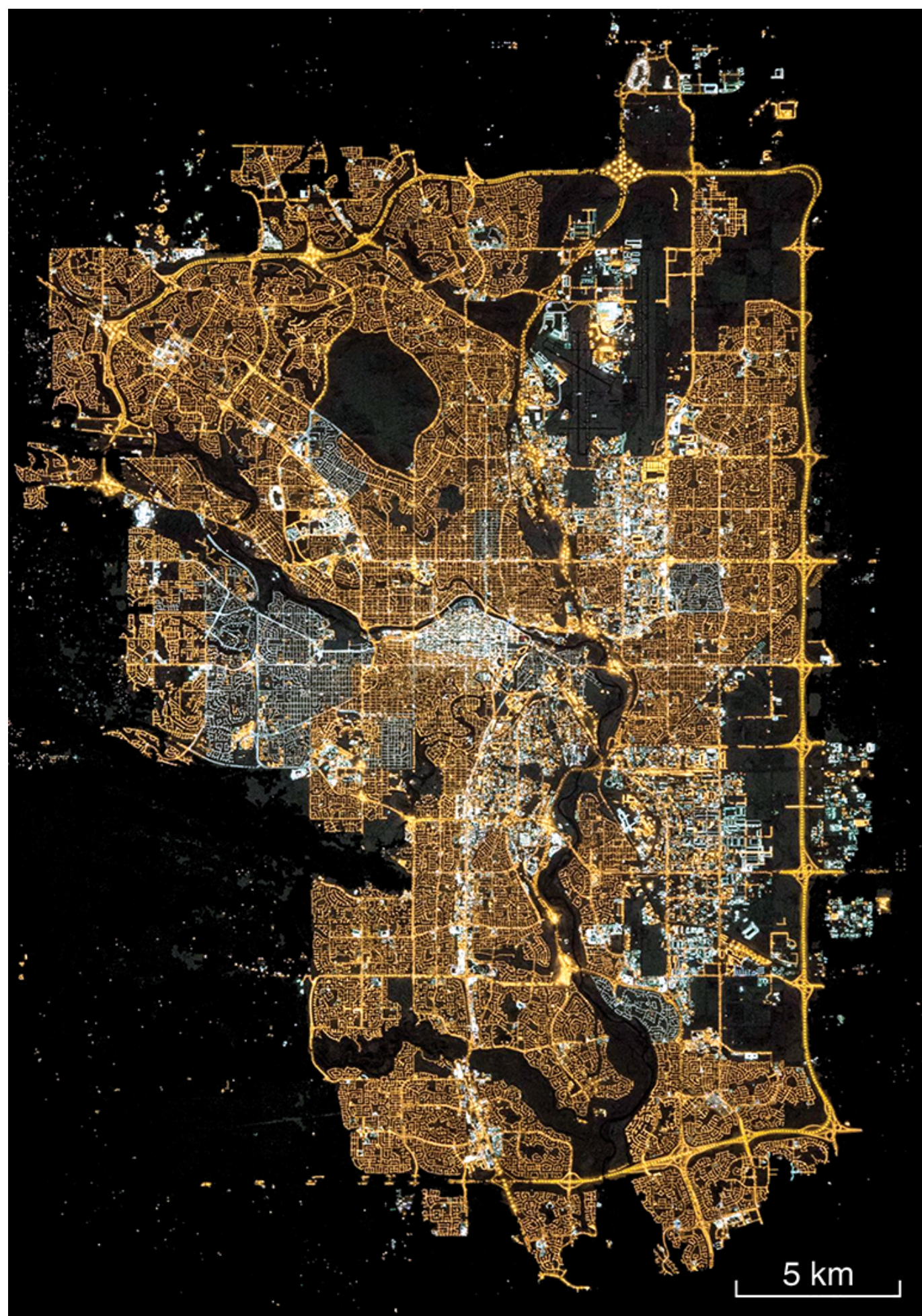

Figure 1. True-color image of the city of Calgary, Canada, obtained by an astronaut aboard the International Space Station at 0707 UTC (12:07 am local time) on 28 November 2015. The image is oriented north up and east at right. National Aeronautics and Space Administration photo ISS045-E-155026. 


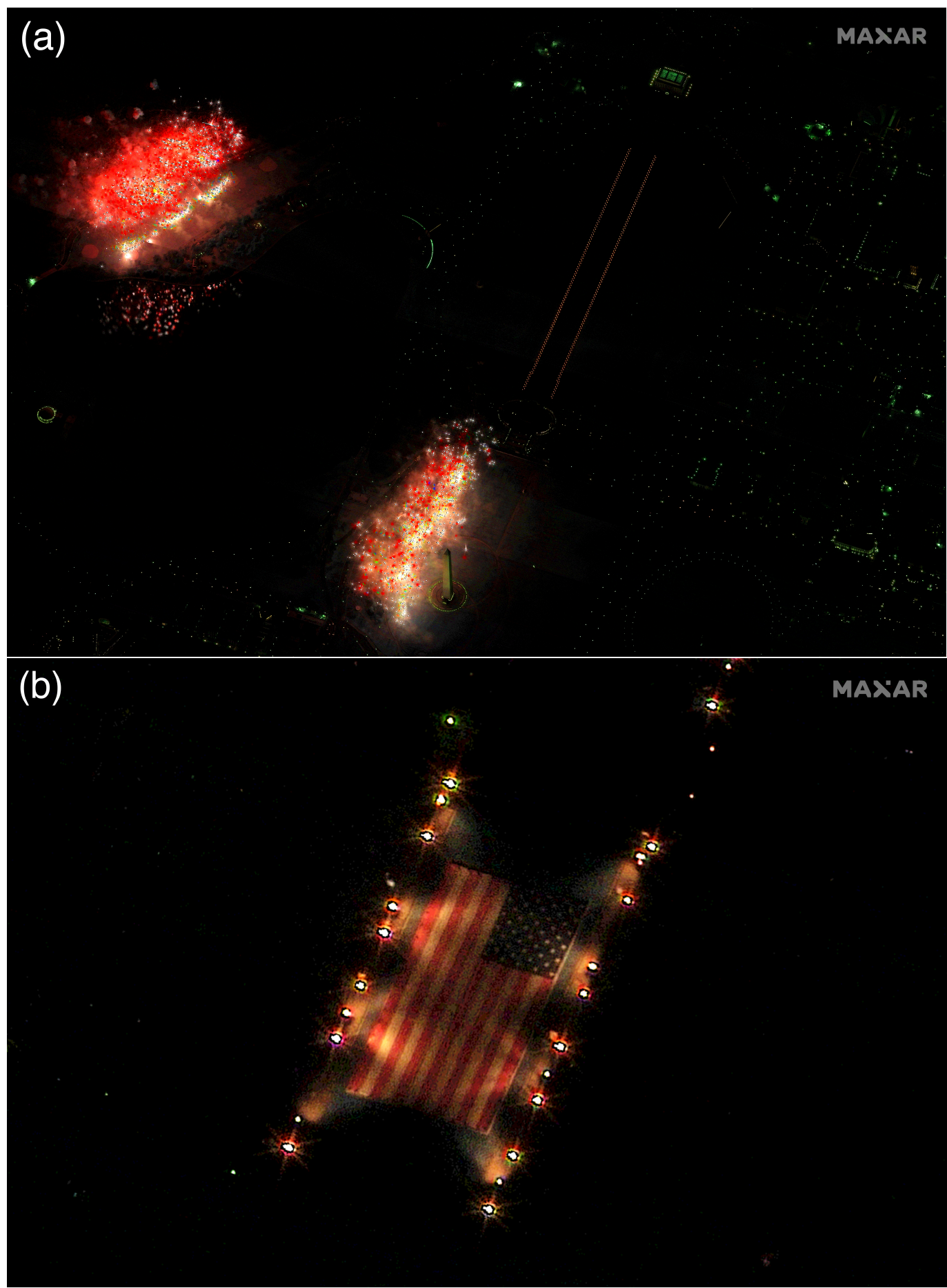

Figure 2. True-color images of the National Mall and vicinity in Washington, U.S., obtained by the Worldview-3 satellite on the night of 20 January 2021. The spatial resolution of this commercial satellite imagery is approximately $1.3 \mathrm{~m}$ per pixel. (a) The brightest parts of this image show a fireworks display held in honor of that day's U.S. Presidential Inauguration. (b) A detailed view of a large American flag displayed on the Mall for the inauguration. Satellite images (C2021 Maxar Technologies, used with permission.

\section{Limitations of Currently Available Data}

The only way to realistically obtain geographically widespread information about the nighttime light emissions from Earth on a regular basis is through satellite remote sensing, but to date there have been no missions dedicated to this purpose with substantial coverage, color information, and publicly available data. Nearly all data available to civilian, non- 
commercial users are from instruments piggybacked on weather satellites and intended mainly to gather data of specifically meteorological or security interests. Although the DMSP-OLS and VIIRS-DNB have together provided global coverage of nighttime lights for a number of decades, they still suffer from a number of limitations that hinder the progress of ALAN research. With existing mission data, the primary shortcomings include a lack of multispectral information, low ground resolution, late or temporally limited overpass times, and insensitivity to short-wavelength light.

DMSP-OLS provided, and the VIIRS-DNB continues to provide, the best continuous, global, useful night-lights monitoring, with a spatial resolution on the order of a few city blocks. Unfortunately, both instruments are effectively blind to short-wavelength light, and in particular to the common white LED spectral power distribution "blue bump" peak near $450 \mathrm{~nm}$. This leaves the dominant satellite remote sensing platform incapable of detecting a significant fraction of the emissions from the fastest-rising sources of nighttime lights across the world in the past decade and creates a distinct gap in our understanding of the problem of light pollution on local to global scales. This lack of information below $500 \mathrm{~nm}$ could give the misleading impression that transitions from warm HPS to bluer LEDs are reducing light pollution when in fact the quantity of total light pollution could be increasing [1]. It also hampers confirmation of the hypothesized economic "rebound effect" relating to global demand for light enabled by the low cost of highly energy-efficient LEDs [1].

Since the DMSP-OLS and VIIRS-DNB instruments are both broadband sensors with a single spectral bandpass each, they provide no spectral information. Most observed ecological and human health impacts of ALAN are highly sensitive to particular segments of the spectrum. Broadband data do not distinguish between wavelengths, so their use is limited in research requiring spectral information. There is a high value to our understanding of light pollution in tracking the evolution of lighting such as during LED retrofits, commercial development, and in seasonal lighting variations. Without spectral information, much of the true effects of these changes are not properly quantified.

Due to the nature of the Sun-synchronous polar orbit of the Suomi-NPP satellite, VIIRS-DNB data are recorded at approximately 1:30 AM local time. This timing is not ideal, since in many instances municipalities and communities reduce their lighting in the later hours of the night. Furthermore, lighting from commercial sources is often turned off or reduced after businesses close in the late evening. The late overpass time of the Suomi-NPP may therefore not accurately capture the true extent of ALAN emissions [11,114,115].

The DMSP-OLS instrument provided a ground sample distance (GSD) of $3 \mathrm{~km} \mathrm{px}^{-1}$. At this resolution, many important features of ALAN sources are lost, and only the largest individual lighting installations can be resolved spatially. The VIIRS-DNB data are an improvement, with a GSD of $750 \mathrm{~m} \mathrm{px}^{-1}$. However, even at this scale, much of the information relevant to the described research goals is not discernible.

There are a number of examples of current or recent remote night light imaging from orbits beyond the DMSP-OLS and VIIRS-DNB instruments. These involve commercial satellites, experimental missions, and photographs from the International Space Station. Table 1 outlines details from a sample of some of these sources. We point to the work of Levin et al. [116] for a more extensive survey of nighttime missions. Where national research-based missions tend to provide the most accessible and consistent sources of data, commercial ventures have demonstrated the potential for vastly improved observations, although for research, data from these missions are restrictive due to the high costs to users. Other experimental or nation-supported efforts have provided data on an ad hoc basis but lack the consistency or access required for proper research. The limitations of astronaut images from the ISS has been addressed above. 
Table 1. Specifications of selected night-lights orbital sensing platforms.

\begin{tabular}{|c|c|c|c|c|c|}
\hline & DMSP-OLS & VIIRS-DNB & LJ1-01 & Worldview-3 & ISS \\
\hline & \multicolumn{2}{|c|}{$\begin{array}{c}1 s t \& \text { 2nd generation } \\
\text { National Facilities }\end{array}$} & $\begin{array}{l}\text { National/ } \\
\text { Commercial }\end{array}$ & $\begin{array}{c}\text { Private } \\
\text { Commercial }\end{array}$ & $\begin{array}{l}\text { Serendipitous } \\
\text { National }\end{array}$ \\
\hline \multirow{3}{*}{$\begin{array}{l}\text { Operational dates } \\
\text { Spatial Resolution } \\
\qquad\left(\mathrm{m} \mathrm{px}^{-1}\right)\end{array}$} & 1992-2013 & 2011-present & 2018-2019 & 2014-present & 2000-present \\
\hline & 2700 & 750 & 130 & 0.31 (panchromatic) & 5 \\
\hline & & & & $\begin{array}{l}1.24 \text { (multispectral) } \\
3.7 \text { (shortwave IR) }\end{array}$ & \\
\hline $\begin{array}{c}\text { Radiometric } \\
\text { Resolution (nm) }\end{array}$ & 400 & 400 & $\leq 82$ & 350 (panchromatic) & 300 \\
\hline $\begin{array}{l}\text { Spectral Sensitivity } \\
(\mu \mathrm{m})\end{array}$ & $0.5-0.9$ & $0.5-0.9$ & $0.46-0.98$ & $0.45-2.365$ & $0.4-0.7$ \\
\hline Spectral Bands & panchromatic & panchromatic & 3 (RGB) & $\begin{array}{l}\text { Panchromatic } \\
8 \text { multispectral } \\
8 \text { shortwave IR }\end{array}$ & 3 (RGB) \\
\hline Dynamic Range (bits) & 6 & 14 & 14 & $\begin{array}{c}11 \text { (panchromatic and multispectral) } \\
14 \text { (shortwave IR) }\end{array}$ & 12 \\
\hline Calibration & $\mathrm{n} / \mathrm{a}$ & on-board & on-board & pre-flight & $\mathrm{n} / \mathrm{a}$ \\
\hline Ground Coverage & global & global & local/regional & global & local/regional \\
\hline $\begin{array}{l}\text { Ground Swath at } \\
\text { nadir }(\mathrm{km})\end{array}$ & $\sim 3000$ & $\sim 3000$ & $\sim 250$ & 13.1 & varied \\
\hline Local Overpass Time & $\sim 19: 30$ & $\sim 01: 30$ & varied & varied & varied \\
\hline
\end{tabular}

Nighttime lights data products from past and present satellite missions are reaching the limit of their utility as the science of ALAN advances. It was precisely because of the data from these missions that the field of ALAN research has grown rapidly in recent decades. Thanks to the DMSP-OLS and VIIRS-DNB instruments, we now have a greater understanding of the hitherto unknown impacts of ALAN on our world. Yet in part, thanks to this increase in knowledge, vital questions go unanswered with our present technology. What is required to meet the needs of the next decade or more of ALAN research is a dedicated, light-pollution-sensing instrument or satellite that can provide dependable, comprehensive, high-quality, publicly available data. The observed growth in anthropogenic nighttime lights [96] and the rapid adoption and conversion to solid-state lighting technologies are two important factors supporting the timeliness of a dedicated ALAN mission. As demonstrated above, a dedicated ALAN sensing mission can provide benefits across a broad range of research fields. All the instrumentation required for this mission is presently available and is at a high technological readiness level.

\section{NITESat Mission Requirements}

With the maturation of small satellite and nanosatellite technologies and instrumentation, as well as the growth of the small satellite industry providing systems in support of those missions over the past few decades, the potential for a dedicated mission focused on the scientific goals in the ALAN research community has become increasingly feasible. As previously mentioned, the 2007 Nightsat concept helped to define the requirements and potential of a dedicated nighttime imaging mission. In the intervening years, great advancements in sensing and satellite systems technologies have been made. We previously described the Night Imaging of Terrestrial Environments Satellite (NITESat), a 2U CubeSat mission concept capable of producing valuable ALAN data [19], but the scale of this concept constrained the quantity and quality of data it could provide. An updated, larger-scale NITESat mission or instrument dedicated to detecting and measuring nighttime lights, can vastly improve on existing orbital remote sensing platforms and provide previously unavailable capabilities.

Here, we outline a number of observational and functional parameters this concept should meet to satisfy the scientific goals outlined in Section 2. These parameters are prioritized to achieve the greatest scientific benefit while keeping in mind that many of 
these factors may result in necessary trade-offs in return value. For example, higher resolution or greater bit depth results in a larger number of data requiring downlink. This may put pressure on the amount of area imaged per overpass or within a unit of time. The requirements summarized below in Table 2 are suggested as a guide for a more extensive and proper engineering trade study. The recommendations in this Section are intended to be used as a minimum guideline for an effective mission.

For each of these parameters, we describe the reasoning in more detail.

Table 2. Parameters ranked by importance for the proposed NITESat mission.

\begin{tabular}{ccc}
\hline Rank & Parameter & Suggested Parameter Value \\
\hline 1 & Ground-Scale Resolution & $10 \mathrm{~m} \mathrm{px}^{-1}$ (optical) \\
2 & Spectral Coverage & Panchromatic 370-870 nm \\
& & 383-503, 493-619, 568-584, 797-833 [117]; \\
& thermal IR \\
3 & Sensitivity & $5 \times 10^{-11} \mathrm{~W} \mathrm{~cm}^{-2} \mathrm{r}^{-1}$ \\
4 & Dynamic Range & $10^{6}$ \\
5 & Coverage & Global land map $\pm 60^{\circ}$ latitude \\
6 & Temporal Sampling & Monthly \\
7 & Mission Duration & 10 years \\
8 & Overpass Times & Varied \\
\hline
\end{tabular}

\subsection{Ground Scale}

For nearly all of the Science Goals outlined above, an improvement in existing groundscale resolution (GSR) would advance the state of research in that field. Any resolution greater than the VIIRS-DNB $750 \mathrm{~m} \mathrm{px}^{-1}$ would improve some aspect of our understanding of ALAN. Benefits gained within the $50-10 \mathrm{~m} \mathrm{px}^{-1}$ range vary according to the specific field of research and question posed. However, a significant improvement in the broad utility of ALAN data could be gained with a GSR of $10 \mathrm{mpx}^{-1}$. A GSR of $\mathbf{1 0 ~ m} \mathbf{p x}^{-1}$ is recommended for a NITESat mission, as it would meet all research goals defined in Section 2. Figure 3 visualizes the improvement gained from an increased GSR. 


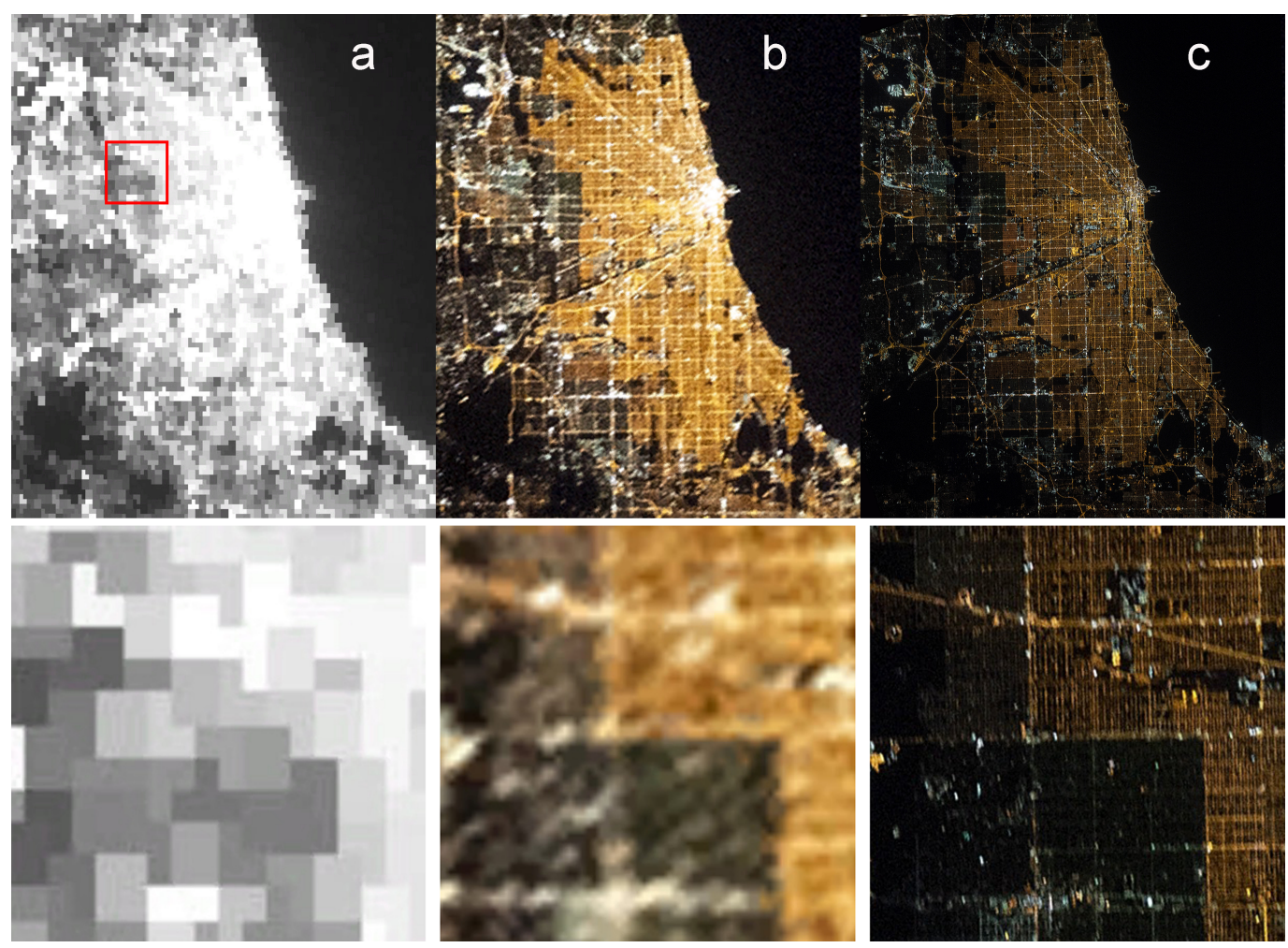

Figure 3. Comparison of resolution and color in remotely sensed nighttime images of Chicago. Each image is $39 \times 48 \mathrm{~km}$. (a) Panchromatic VIIRS-DNB data (14 November 2020) $740 \mathrm{~m} \mathrm{px}^{1}$; (b) ISS RGB image (ISS050-E-029303) at $100 \mathrm{~m} \mathrm{px}^{1}$ and (c) ISS RGB image (ISS046-E-025710) at $25 \mathrm{~m} \mathrm{px}^{1}$ resolution. The red box is the location of the $6 \times 6 \mathrm{~km}$ insets shown below each image (North is up).

\subsection{Spectral Coverage}

Presently, no consistent global ALAN data from orbit provide the spectral definition required to distinguish the types of light sources. This is one of the most critical needs in a "color-changing world" [118] and for many aspects of ALAN research. Regarding specific spectral bands, we refer to the recommendations in the 2020 paper of de Meester and Storch, "Optimized Performance Parameters for Nighttime Multispectral Satellite Imagery to Analyze Lightings in Urban Areas."

Based on their work, we recommend that the NITESat mission should provide four color channels (at 383-503, 493-619, 568-584 and 797-833 $\mathrm{nm}$ ) with a panchromatic band $(370-870 \mathrm{~nm})$, as these would meet all of the needs of the science questions described in Section 2. de Meester and Storch argue that these four passbands are the minimum set required to discriminate various lamp types from satellite remote sensing data. The wavelength ranges are chosen so as to include or exclude specific features in the spectral power distributions of existing and legacy lamp types. The addition of a panchromatic channel allows approximating the VIIRS-DNB passband by subtracting the blue channel (383-503 nm) from the panchromatic channel. It also fills gaps between the four color channels and helps to "future-proof" the NITESat mission by accommodating future changes to lamp technology.

The value added by a $\sim 10 \mu \mathrm{m}$ thermal IR band for cloud and fire detection is also recognized, and the addition of such a band is recommended. Cloud detection is useful for determining which pixels represent "clear sky" conditions for evaluating data quality and does not depend on achieving the same GSR as the optical channels. Fire detection, whether from oil/gas production or wildfire, helps quickly discriminate between such light sources and transient sources of artificial (optical) light. 


\subsection{Sensitivity}

Biological effects of ALAN on humans and other animals have been observed in laboratory experiments at illuminances at 0.1 lux and lower [119]—less than ambient moonlight [120]. To determine whether this applies in the natural environment, we must collect data at the lowest levels expected in environments unaffected by anthropogenic contamination. From orbit, natural sources (airglow, diffuse starlight, zodiacal light, etc.) create a lower limit on how dark a nighttime Earth environment can be. This baseline should be the "floor" of the detection limit from the NITESat mission. The lowest observable signal from the Earth's surface with the addition of atmospheric radiance is nearly $1 \times 10^{-10} \mathrm{~W} \mathrm{~cm}^{-2} \mathrm{sr}^{-1}$ [121]. To distinguish the baseline level from detector noise at a signal-to-noise ratio (SNR) of 2:1, an optimal target of $5 \times 10^{-11} \mathrm{~W} \mathrm{~cm}^{-2} \mathrm{sr}^{-1}$ is recommended for the NITESat data product, which would address the needs of all questions outlined in Section 2. In specifying a radiance sensitivity threshold and minimum SNR, we indirectly take into account issues such as stray light that are known to have affected earlier missions.

\subsection{Dynamic Range}

The range of nighttime brightness from the lowest natural nighttime environment to the brightest pixel level sources within urban cores can span a range of nearly six orders of magnitude. To be able to properly quantify and characterize ALAN in context, it is recommended that the NITESat mission capture a range of six orders of magnitude (from $10^{-10}$ to $10^{-4} \mathrm{~W} \mathrm{~cm}^{-2} \mathrm{sr}^{-1}$ ) without saturation or loss of definition in low-SNR scenarios to meet nearly all Science Goals in Section 2. The addition of unsaturated data two orders of magnitude higher would add benefit for observations of unique outliers such as gas flares, fishing lights, and other individual sources that exceed even the brightest urban centers.

\subsection{Coverage}

ALAN is by definition anthropogenic, and since over $95 \%$ of the world's population lives between $60^{\circ} \mathrm{N}$ and $60^{\circ} \mathrm{S}$ latitude, this is where data are most important for research [122]. ALAN generated at sea is well known, yet if ocean observations were required by this mission, the scale of data needed to be collected would increase by nearly 2.5 times. At a minimum, the NITESat mission should provide at least one cloudless pass per year of $100 \%$ of the Earth's land surface between the latitudes of $60^{\circ} \mathrm{N}$ and $60^{\circ} \mathrm{S}$. A low-Earth orbit near $60^{\circ}$ inclination, as recommended for the NITESat mission, would sufficiently capture nearly all observable locations relevant to the research defined in this paper.

\subsection{Temporal Sampling}

Some of the science questions outlined here can be satisfied by a single annual dataset, while others require a higher frequency of observations. A satellite in non-Sun-synchronous LEO can provide observations over any one location multiple times within any one year and at various times of the night. This can afford opportunities for research requiring observations with higher temporal sampling than annual or monthly maps. It is recommended that the NITESat mission has an average temporal sampling of no less than once per month under cloud-free conditions over any land imaged as this would satisfy to some degree all science questions outlined above.

\subsection{Mission Duration}

In order to monitor trends in the development and evolution of LP as well as for longer-term ecological impacts, a sufficient time in orbit is required. A minimum of 5 years is needed for a mission to collect data in order to properly investigate time-dependent features of ALAN. It is recommended that NITESat be a 10-year mission as this would satisfy to a sufficient degree all the questions posed in Section 2. 


\subsection{Overpass Times}

The Suomi-NPP and DMSP satellites are/were both in Sun-synchronous orbits. This results in observations that are relatively fixed at the same local time each night. Since most locations on Earth receive one overpass per night at the same local time, exploring effects that occur throughout the night make it impossible to do effective time-resolved studies with a cadence of less than $24 \mathrm{~h}$. Stable observation times help in the analysis of certain aspects of long-term trends in light emission, yet these data are provided relatively well by the VIIRS instrument. With this in mind, the NITESat mission should provide observations at all times when opportune. Although observations from Low Earth Orbit (LEO) would be stochastic in nature, a NITESat mission in LEO is recommended, as it would be able to image locations at various times of the night, and over longer periods of time coverage, the observations would build sufficiently to meet the needs for most of the Science Goals outlined above.

\subsection{Calibration}

Lack of an on-board reference has been a problem with VIIRS-DNB and particularly the DMSP-OLS data products. Ground-source calibration can be done with stable light sources. One such experiment demonstrated this possibility with the DMSP-OLS instrument using a controlled isolated light source [123]. Although we do not define the specific methods here, the NITESat mission should have a robust, dependable method for instrument calibration throughout the duration of its mission.

\section{Science Traceability Matrix}

To validate the Mission Requirements defined by the Science Goals, the Science Traceability Matrix (Figure 4) maps those goals to the individual mission parameters outlined. Each research question is referenced by its corresponding identifier from the Science Goals section in the subjects of Ecology (EL), Environment (EV), Economy (EO), Policy (P), Safety (S), Health $(\mathrm{H})$ and Characterization $(\mathrm{C})$. For each question, its requirement is noted for each Minimum Parameter described in the NITESat Mission Requirements section.

Each parameter is color-coded to reflect how well it satisfies the requirement of that particular science question. Green indicates it Satisfies the question. Yellow means it Improves On the present knowledge of that question, and Red indicates it May Not Satisfy the requirements of that question. Since the Mission Requirements were driven by and defined to optimize the scientific results, no parameter falls below the Improves On level. 


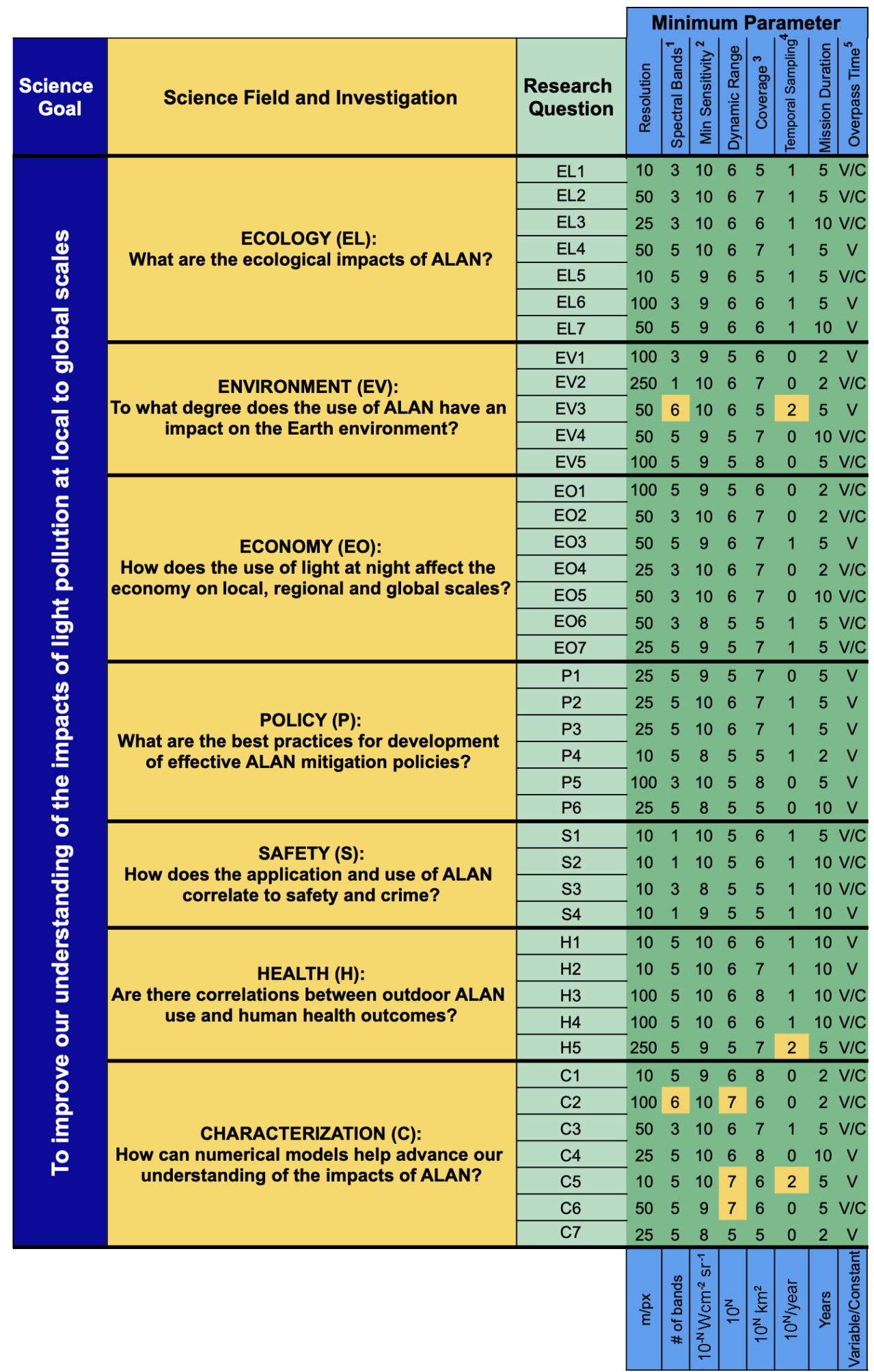

Figure 4. Science Traceability Matrix for the NITESat mission. For research questions, see reference number from Section: Science Goals. Parameters in green Satisfy that question; those in yellow Improve On the question. The notes for the "Minimum Parameters" columns are as follows: (1) Spectral Bands: 1 = Broadband, 3 = RGB, $4=$ RGB + Broadband, $5=$ de Meester, 6 = de Meester + IR; (2) Minimum Sensitivity: $10=$ Airglow, $9=\geq 50 \%$ Lunar Phase, $8=$ Rural; (3) Coverage: 9 = Land + Sea, $8=$ Global Land, $7=$ National, $6=$ Regional, $5=$ Local; (4) Temporal Sampling: 0 = Annual, 1 = Monthly, 3 = Nightly, 4 = Multiple Nightly; and (5) Overpass Time: $\mathrm{V}=$ Variable, $\mathrm{C}=$ Constant, $\mathrm{V} / \mathrm{C}=$ No Preference. 


\section{Discussion}

The state of ALAN research in regards to data provided by remote sensing from satellites can undeniably benefit from new missions or instrumentation. There are many potential approaches to improve our understanding of ALAN across many disciplines. Although we expect that a successful mission is achievable in a smallsat-class facility, the fundamental science drivers described within could also be satisfied to varying degrees by a number of different mission concepts. For instance, a constellation of CubeSats could provide improved coverage and better time-dependent observations, perhaps at the cost of lower resolution. However, the benefits should be weighed based on the Science Goals intended. Another mission concept involving a series of nanosatellite missions would offer more coverage and a better opportunity for time dependent observations-even resolving events and trends within a single night.

A dedicated instrument for ALAN observation could benefit by being a component of a medium to large class mission. Sharing the power, communications, and other operational systems from such a mission would reduce infrastructure overhead and potentially offer expanded capabilities of the scientific payload. As larger-scale missions such as the SuomiNPP are less frequently funded, more competitive for proposal acceptance and more limited in-flight parameters (a "get what you're given" situation), there may be substantial trade-offs in this scenario. An instrument on board a larger research mission would be worthy of study.

On average, the ISS passes over the Earth at night sixteen times a "day". Some of the best imagery we have of the Earth at night are from photographs taken by astronauts on the ISS using off-the-shelf, commercial DSLR cameras. One could imagine the same level of instrumentation mounted to the ISS and automated to collect ALAN data. This concept has been explored, and it has a level of advantages and disadvantages over a dedicated mission. Although the ISS affords a reliable platform for instrumentation, there remain hurdles in terms of hardware integration and limited global ground coverage.

What we propose here is a feasible solution to the bottleneck in data for ALAN research. It is by no means a definitive solution to the advancement of remote sensing of nighttime lights. Images from the Maxar Technologies WorldView-3 satellite, shown in Figure 2, have demonstrated the capability of observing the Earth at night at a resolution far beyond what is proposed in this paper. VIIRS-DNB demonstrates the ability to collect global nightly maps of ALAN sources. The technologies are available. In this paper, we lay out the scientific case for a dedicated ALAN mission, but a detailed engineering study with trade-offs and detailed analysis is ultimately required. Only a rigorous engineering study can validate the feasibility of the entire suite of recommendations we propose.

\section{Summary}

Light pollution is a novel, significant, and global environmental threat that ranks among the defining characteristics of a proposed geologic era known as the "Anthro-

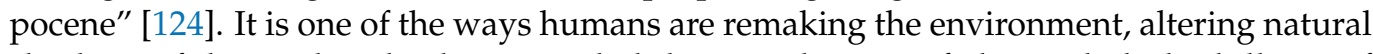
rhythms of day and night that preceded the introduction of electric light by billions of years. The use of ALAN has grown exponentially in recent years, resulting in part from the rapid proliferation of cheap and highly energy-efficient solid-state lighting products that further fuel elastic consumer demand for light at night.

Satellite remote sensing of night lights remains our only effective means of understanding the problem of light pollution on a truly planetary scale, yet to date, no satellite mission truly optimized for measuring ALAN from space has ever flown. Researchers are left wanting for the ideal spatial resolution, spectral coverage, frequency of overpass times, and ground coverage, among other variables, that, if available, would contribute meaningfully to answering key science questions. Questions as important as how light pollution alters ecosystems, impacts human health, has a direct bearing on economies and the global environment, and makes our lives safer or more sustainable can all be addressed by a dedicated mission as outlined here. Additionally, a properly designed 
mission can advance our future framework of understanding of this global and growing concern. The unfulfilled need is all the more acute as the clock runs out on the solid-state lighting revolution in the 2020s and with it the chance to study what is arguably the most significant technological shift in outdoor lighting since its introduction over a century ago.

We have here described the Science Goals and mission requirements for a Nighttime Imaging of Terrestrial Environments Satellite, or NITESat. This mission leverages existing technologies deployed in previous missions in which the remote sensing of nighttime lights was at best a secondary objective. Such mission designs were therefore not optimized for the purpose of observing night lights; we propose a new mission with this as its primary mission. NITESat in particular improves on the ground-scale resolution and spectral coverage of previous missions and would add varied overpass times to address a broader set of science questions than was possible in earlier cases. We argue that these capabilities constitute a new way to see the phenomenon of night lights.

We find that the NITESat concept can be effective in opening new fronts in investigations of ALAN's effects across a wide array of science topics. However, its appeal ranges well beyond basic research. NITESat is a tool enabling better land use policy, urban planning, and resource monitoring and conservation. Considering its potential social and scientific benefits, and given the abundance of unknowns among the science questions we have outlined here, we conclude that the time for the mission we describe here is now.

Author Contributions: Conceptualization, J.C.B. and K.W.; writing-original draft preparation, J.C.B., K.W., G.G. and C.T; writing-review and editing, J.C.B., K.W., G.G., C.T. and T.L. All authors have read and agreed to the published version of the manuscript.

Funding: This research received no external funding.

Institutional Review Board Statement: Not applicable.

Informed Consent Statement: Not applicable.

Data Availability Statement: Not applicable.

Acknowledgments: The authors thank the following researchers for consultations and advice during the preparation of this paper: Martin Aubé (Cégep de Sherbrooke); George Brainard (Thomas Jefferson University); Ronald Gibbons and Rajaram Bhagavathula (Virginia Tech Transportation Institute); and Paul Marchant (University of Leeds).

Conflicts of Interest: The authors declare no conflict of interest.

\section{Abbreviations}

The following abbreviations are used in this manuscript:

$\begin{array}{ll}\text { ALAN } & \text { Artificial light at night } \\ \text { DNB } & \text { Day-Night Band } \\ \text { DMSP } & \text { Defense Meteorological Satellite Program } \\ \text { HPS } & \text { High-pressure sodium } \\ \text { LEO } & \text { Low-Earth Orbit } \\ \text { NASA } & \text { National Aeronautics and Space Administration } \\ \text { NASEM } & \text { National Academies of Sciences, Engineering and Medicine } \\ \text { NPP } & \text { National Polar-orbiting Partnership } \\ \text { NTL } & \text { Nighttime lights } \\ \text { OLS } & \text { Operational Line-Scan System } \\ \text { SMD } & \text { Science Mission Directorate } \\ \text { SSL } & \text { Solid-state lighting } \\ \text { VIIRS } & \text { Visible Infrared Imaging Radiometer Suite }\end{array}$

\section{References}

1. Kyba, C.C.M.; Kuester, T.; de Miguel, A.S.; Baugh, K.; Jechow, A.; Hölker, F.; Bennie, J.; Elvidge, C.D.; Gaston, K.J.; Guanter, L. Artificially lit surface of Earth at night increasing in radiance and extent. Sci. Adv. 2017, 3, e1701528. [CrossRef] [PubMed]

2. Rich, C.; Longcore, T. (Eds.) Ecological Consequences of Artificial Night Lighting; Island Press: Washington, DC, USA, 2006. 
3. Kumar, P.; Ashawat, M.S.; Pandit, V.; Sharma, D.K. Artificial Light Pollution at Night: A Risk for Normal Circadian Rhythm and Physiological Functions in Humans. Curr. Environ. Eng. 2019, 6, 111-125. [CrossRef]

4. Kyba, C.C.M.; Tong, K.P.; Bennie, J.; Birriel, I.; Birriel, J.J.; Cool, A.; Danielsen, A.; Davies, T.W.; den Outer, P.N.; Edwards, W.; et al. Worldwide variations in artificial skyglow. Sci. Rep. 2015, 5, 8409. [CrossRef] [PubMed]

5. Fotios, S.; Gibbons, R. Road lighting research for drivers and pedestrians: The basis of luminance and illuminance recommendations. Light. Res. Technol. 2018, 50, 154-186. [CrossRef]

6. Barentine, J.; Kieda, D.; Goldsmith, S.; Foott, B.; Muir, J. The Consortium for Dark Sky Studies: A Transdisciplinary Institute for Understanding the Loss of the Night. In Proceedings of the

American Astronomical Society Meeting, National Harbor, MD, USA, 8-12 January 2018; Abstract \#231; Volume 231, p. 142.01.

7. University of Utah Launches First-Ever Journal of Dark Sky Studies. Available online: https://unews.utah.edu/journal-of-darksky-studies/ (accessed on 27 August 2019).

8. Acuto, M. We need a science of the night. Nature 2019, 576, 339. [CrossRef]

9. Kyba, C.C.; Pritchard, S.B.; Ekirch, A.R.; Eldridge, A.; Jechow, A.; Preiser, C.; Kunz, D.; Henckel, D.; Hölker, F.; Barentine, J.; et al. Night Matters-Why the Interdisciplinary Field of "Night Studies" Is Needed. J. Multidiscip. Sci. J. 2020, 3, 1. [CrossRef]

10. Cao, C.; Luccia, F.J.D.; Xiong, X.; Wolfe, R.; Weng, F. Early On-Orbit Performance of the Visible Infrared Imaging Radiometer Suite Onboard the Suomi National Polar-Orbiting Partnership (S-NPP) Satellite. IEEE Trans. Geosci. Remote Sens. 2014, 52, 1142-1156. [CrossRef]

11. Kyba, C.; Garz, S.; Kuechly, H.; de Miguel, A.; Zamorano, J.; Fischer, J.; Hölker, F. High-Resolution Imagery of Earth at Night: New Sources, Opportunities and Challenges. Remote Sens. 2014, 7, 1-23. [CrossRef]

12. Grubisic, M.; Haim, A.; Bhusal, P.; Dominoni, D.M.; Gabriel, K.M.A.; Jechow, A.; Kupprat, F.; Lerner, A.; Marchant, P.; Riley, W.; et al. Light Pollution, Circadian Photoreception, and Melatonin in Vertebrates. Sustainability 2019, 11, 6400. [CrossRef]

13. Kim, Y.J.; Lee, E.; Lee, H.S.; Kim, M.; Park, M.S. High prevalence of breast cancer in light polluted areas in urban and rural regions of South Korea: An ecologic study on the treatment prevalence of female cancers based on National Health Insurance data. Chronobiol. Int. 2015, 32, 657-667. [CrossRef]

14. Portnov, B.A.; Stevens, R.G.; Samociuk, H.; Wakefield, D.; Gregorio, D.I. Light at night and breast cancer incidence in Connecticut: An ecological study of age group effects. Sci. Total Environ. 2016, 572, 1020-1024. [CrossRef]

15. James, P.; Bertrand, K.A.; Hart, J.E.; Schernhammer, E.S.; Tamimi, R.M.; Laden, F. Outdoor Light at Night and Breast Cancer Incidence in the Nurses' Health Study II. Environ. Health Perspect. 2017, 125, 087010. [CrossRef]

16. Zhong, C.; Franklin, M.; Wiemels, J.; McKean-Cowdin, R.; Chung, N.T.; Benbow, J.; Wang, S.S.; Lacey, J.V.; Longcore, T. Outdoor artificial light at night and risk of non-Hodgkin lymphoma among women in the California Teachers Study cohort. Cancer Epidemiol. 2020, 69, 101811. [CrossRef]

17. 5 Species Threatened by Light Pollution. Available online: https://www.darksky.org/5-species-threatened-by-light-pollution/ (accessed on 23 June 2016).

18. Lewis, S.M.; Wong, C.H.; Owens, A.C.S.; Fallon, C.; Jepsen, S.; Thancharoen, A.; Wu, C.; Cock, R.D.; Novák, M.; López-Palafox, T.; et al. A Global Perspective on Firefly Extinction Threats. BioScience 2020, 70, 157-167. [CrossRef]

19. Walczak, K.; Gyuk, G.; Kruger, A.; Byers, E.; Huerta, S. NITESat: A High Resolution, Full-Color, Light Pollution Imaging Satellite Mission. Int. J. Sustain. Light. 2017, 19, 48-55. [CrossRef]

20. National Academies of Sciences, Engineering and Medicine. Thriving on Our Changing Planet: A Decadal Strategy for Earth Observation from Space; National Academies Press: Washington, DC, USA, 2018. [CrossRef]

21. Stark, H.; Brown, S.S.; Wong, K.W.; Stutz, J.; Elvidge, C.D.; Pollack, I.B.; Ryerson, T.B.; Dube, W.P.; Wagner, N.L.; Parrish, D.D. City lights and urban air. Nat. Geosci. 2011, 4,730-731. [CrossRef]

22. Johnson, R.S.; Zhang, J.; Hyer, E.J.; Miller, S.D.; Reid, J.S. Preliminary investigations toward nighttime aerosol optical depth retrievals from the VIIRS Day/Night Band. Atmos. Meas. Tech. 2013, 6, 1245-1255. [CrossRef]

23. Tong, K.P.; Kyba, C.C.; Heygster, G.; Kuechly, H.U.; Notholt, J.; Kolláth, Z. Angular distribution of upwelling artificial light in Europe as observed by Suomi-NPP satellite. J. Quant. Spectrosc. Radiat. Transf. 2020, 249, 107009. [CrossRef]

24. De Miguel, A.S.; Kyba, C.C.M.; Zamorano, J.; Gallego, J.; Gaston, K.J. The nature of the diffuse light near cities detected in nighttime satellite imagery. Sci. Rep. 2020, 10, 7829. [CrossRef]

25. Duriscoe, D.M.; Anderson, S.J.; Luginbuhl, C.B.; Baugh, K.E. A simplified model of all-sky artificial sky glow derived from VIIRS Day/Night band data. J. Quant. Spectrosc. Radiat. Transf. 2018, 214, 133-145. [CrossRef]

26. Zurbuchen, T. Science 2020-2024: A Vision for Scientific Excellence; Technical Report; National Aeronautics and Space Administration:

Washington, DC, USA, 2020.

27. Sanders, D.; Frago, E.; Kehoe, R.; Patterson, C.; Gaston, K.J. A meta-analysis of biological impacts of artificial light at night. Nat. Ecol. Evol. 2020, 5, 74-81. [CrossRef]

28. Dacke, M.; Baird, E.; Byrne, M.; Scholtz, C.H.; Warrant, E.J. Dung Beetles Use the Milky Way for Orientation. Curr. Biol. 2013, 23, 298-300. [CrossRef] [PubMed]

29. Polak, T.; Korine, C.; Yair, S.; Holderied, M.W. Differential effects of artificial lighting on flight and foraging behaviour of two sympatric bat species in a desert. J. Zool. 2011, 285, 21-27. [CrossRef] 
30. Rubolini, D.; Maggini, I.; Ambrosini, R.; Imperio, S.; Paiva, V.H.; Gaibani, G.; Saino, N.; Cecere, J.G. The Effect of Moonlight on Scopoli's Shearwater Calonectris diomedea Colony Attendance Patterns and Nocturnal Foraging: A Test of the Foraging Efficiency Hypothesis. Ethology 2014, 121, 284-299. [CrossRef]

31. Silva, A.D.; Diez-Méndez, D.; Kempenaers, B. Effects of experimental night lighting on the daily timing of winter foraging in common European songbirds. J. Avian Biol. 2017, 48, 862-871. [CrossRef]

32. Farnworth, B.; Innes, J.; Waas, J.R. Converting Predation Cues into Conservation Tools: The Effect of Light on Mouse Foraging Behaviour. PLoS ONE 2016, 11, e0145432. [CrossRef] [PubMed]

33. Downs, N.; Beaton, V.; Guest, J.; Polanski, J.; Robinson, S.; Racey, P. The effects of illuminating the roost entrance on the emergence behaviour of Pipistrellus pygmaeus. Biol. Conserv. 2003, 111, 247-252. [CrossRef]

34. Petrželková, K.J.; Downs, N.C.; Zukal, J.; Racey, P.A. A comparison between emergence and return activity in pipistrelle bats Pipistrellus pipistrellus and P. pygmaeus. Acta Chiropterol. 2006, 8, 381-390. [CrossRef]

35. Stone, E.L.; Jones, G.; Harris, S. Street Lighting Disturbs Commuting Bats. Curr. Biol. 2009, 19, 1123-1127. [CrossRef]

36. Kurvers, R.H.J.M.; Drägestein, J.; Hölker, F.; Jechow, A.; Krause, J.; Bierbach, D. Artificial Light at Night Affects Emergence from a Refuge and Space Use in Guppies. Sci. Rep. 2018, 8, 14131. [CrossRef]

37. Vignoli, L.; Luiselli, L. Better in the dark: Two Mediterranean amphibians synchronize reproduction with moonlit nights. Web Ecol. 2013, 13, 1-11. [CrossRef]

38. Agarwal, N.; Srivastava, S.; Malik, S.; Rani, S.; Kumar, V. Altered light conditions during spring: Effects on timing of migration and reproduction in migratory redheaded bunting (Emberiza bruniceps). Biol. Rhythm Res. 2015, 46, 647-657. [CrossRef]

39. Robert, K.A.; Lesku, J.A.; Partecke, J.; Chambers, B. Artificial light at night desynchronizes strictly seasonal reproduction in a wild mammal. Proc. R. Soc. B Biol. Sci. 2015, 282, 20151745. [CrossRef] [PubMed]

40. Tallec, T.L.; Théry, M.; Perret, M. Melatonin concentrations and timing of seasonal reproduction in male mouse lemurs (Microcebus murinus) exposed to light pollution. J. Mammal. 2016, 97, 753-760. [CrossRef]

41. Miller, M.W. Apparent Effects of Light Pollution on Singing Behavior of American Robins. Condor 2006, 108, 130-139. [CrossRef]

42. Geffen, K.G.V.; Groot, A.T.; van Grunsven, R.H.A.; Donners, M.; Berendse, F.; Veenendaal, E.M. Artificial night lighting disrupts sex pheromone in a noctuid moth. Ecol. Entomol. 2015, 40, 401-408. [CrossRef]

43. Borges, R.M. Dark Matters: Challenges of Nocturnal Communication Between Plants and Animals in Delivery of Pollination Services. Yale J. Biol. Med. 2018, 9, 33-42.

44. Doren, B.M.V.; Horton, K.G.; Dokter, A.M.; Klinck, H.; Elbin, S.B.; Farnsworth, A. High-intensity urban light installation dramatically alters nocturnal bird migration. Proc. Natl. Acad. Sci. USA 2017, 114, 11175-11180. [CrossRef]

45. Ditmer, M.A.; Stoner, D.C.; Francis, C.D.; Barber, J.R.; Forester, J.D.; Choate, D.M.; Ironside, K.E.; Longshore, K.M.; Hersey, K.R.; Larsen, R.T.; et al. Artificial nightlight alters the predator-prey dynamics of an apex carnivore. Ecography 2020, 44, 149-161. [CrossRef]

46. Simons, A.L.; Yin, X.; Longcore, T. High correlation but high scale-dependent variance between satellite measured night lights and terrestrial exposure. Environ. Res. Commun. 2020, 2, 021006. [CrossRef]

47. Perry, G.; Fisher, R. Night lights and reptiles: Observed and potential effects. In Ecological Consequences of Artificial Night Lighting; Rich, C., Longcore, T., Eds.; Island Press: Washington, DC, USA, 2006; pp. 169-191.

48. Vanderbilt, K.; Gaiser, E. The International Long Term Ecological Research Network: A platform for collaboration. Ecosphere 2017, 8, e01697. [CrossRef]

49. Keller, M.; Schimel, D.S.; Hargrove, W.W.; Hoffman, F.M. A continental strategy for the National Ecological Observatory Network. Front. Ecol. Environ. 2008, 6, 282-284. [CrossRef]

50. Horton, K.G.; Nilsson, C.; Doren, B.M.V.; Sorte, F.A.L.; Dokter, A.M.; Farnsworth, A. Bright lights in the big cities: Migratory birds' exposure to artificial light. Front. Ecol. Environ. 2019, 17, 209-214. [CrossRef]

51. Owens, A.C.; Cochard, P.; Durrant, J.; Farnworth, B.; Perkin, E.K.; Seymoure, B. Light pollution is a driver of insect declines. Biol. Conserv. 2020, 241, 108259. [CrossRef]

52. Longcore, T.; Rodríguez, A.; Witherington, B.; Penniman, J.F.; Herf, L.; Herf, M. Rapid assessment of lamp spectrum to quantify ecological effects of light at night. J. Exp. Zool. Part Ecol. Integr. Physiol. 2018, 329, 511-521. [CrossRef]

53. Brown, R. World On the Edge: How to Prevent Environmental and Economic Collapse; W. W. Nortion \& Company: New York, NY, USA, 2010.

54. IEA. Light's Labour's Lost: Policies for Energy-Efficient Lighting; Technical Report; International Energy Agency: Paris, France, 2006. [CrossRef]

55. IEA. World Energy Outlook; Technical Report; International Energy Agency: Paris, France, 2006. [CrossRef]

56. Elliott, C.; Lee, K. Adoption of Light-Emitting Diodes in Common Lighting Applications; Technical Report; U.S. Department of Energy: Washington, DC, USA, 2020.

57. Asefi-Najafabady, S.; Rayner, P.J.; Gurney, K.R.; McRobert, A.; Song, Y.; Coltin, K.; Huang, J.; Elvidge, C.; Baugh, K. A multiyear, global gridded fossil fuel CO2 emission data product: Evaluation and analysis of results. J. Geophys. Res. Atmos. 2014, 119, 10213-10231. [CrossRef]

58. Kyba, C.C.M.; Hänel, A.; Hölker, F. Redefining efficiency for outdoor lighting. Energy Environ. Sci. 2014, 7, 1806-1809. [CrossRef]

59. Xie, Y.; Weng, Q.; Fu, P. Temporal variations of artificial nighttime lights and their implications for urbanization in the conterminous United States, 2013-2017. Remote Sens. Environ. 2019, 225, 160-174. [CrossRef] 
60. Chen, X.; Nordhaus, W.D. VIIRS Nighttime Lights in the Estimation of Cross-Sectional and Time-Series GDP. Remote Sens. 2019, 11, 1057. [CrossRef]

61. Falchetta, G.; Pachauri, S.; Parkinson, S.; Byers, E. A high-resolution gridded dataset to assess electrification in sub-Saharan Africa. Sci. Data 2019, 6, 110. [CrossRef]

62. Jasiński, T. Modeling electricity consumption using nighttime light images and artificial neural networks. Energy 2019, 179, 831-842. [CrossRef]

63. Fehrer, D.; Krarti, M. Spatial distribution of building energy use in the United States through satellite imagery of the earth at night. Build. Environ. 2018, 142, 252-264. [CrossRef]

64. Levin, N.; Ali, S.; Crandall, D. Utilizing remote sensing and big data to quantify conflict intensity: The Arab Spring as a case study. Appl. Geogr. 2018, 94, 1-17. [CrossRef]

65. Levin, N.; Ali, S.; Crandall, D.; Kark, S. World Heritage in danger: Big data and remote sensing can help protect sites in conflict zones. Glob. Environ. Chang. 2019, 55, 97-104. [CrossRef]

66. Román, M.O.; Stokes, E.C.; Shrestha, R.; Wang, Z.; Schultz, L.; Carlo, E.A.S.; Sun, Q.; Bell, J.; Molthan, A.; Kalb, V.; et al. Satellite-based assessment of electricity restoration efforts in Puerto Rico after Hurricane Maria. PLoS ONE 2019, 14, e0218883. [CrossRef]

67. Heger, M.P.; Neumayer, E. The impact of the Indian Ocean tsunami on Aceh's long-term economic growth. J. Dev. Econ. 2019, 141, 102365. [CrossRef]

68. Garcia-Saenz, A.; de Miguel, A.S.; Espinosa, A.; Valentin, A.; Aragonés, N.; Llorca, J.; Amiano, P.; Sánchez, V.M.; Guevara, M.; Capelo, R.; et al. Evaluating the Association between Artificial Light-at-Night Exposure and Breast and Prostate Cancer Risk in Spain (MCC-Spain Study). Environ. Health Perspect. 2018, 126, 047011. [CrossRef]

69. Khan, Z.A.; Yumnamcha, T.; Mondal, G.; Devi, S.D.; Rajiv, C.; Labala, R.K.; Devi, H.S.; Chattoraj, A. Artificial Light at Night (ALAN): A Potential Anthropogenic Component for the COVID-19 and HCoVs Outbreak. Front. Endocrinol. 2020, 11, 622. [CrossRef]

70. Ghosh, T.; Anderson, S.; Elvidge, C.; Sutton, P. Using Nighttime Satellite Imagery as a Proxy Measure of Human Well-Being. Sustainability 2013, 5, 4988-5019. [CrossRef]

71. Guetté, A.; Godet, L.; Juigner, M.; Robin, M. Worldwide increase in Artificial Light At Night around protected areas and within biodiversity hotspots. Biol. Conserv. 2018, 223, 97-103. [CrossRef]

72. Xu, P.; Wang, Q.; Jin, J.; Jin, P. An increase in nighttime light detected for protected areas in mainland China based on VIIRS DNB data. Ecol. Indic. 2019, 107, 105615. [CrossRef]

73. Hyde, E.; Frank, S.; Barentine, J.C.; Kuechly, H.; Kyba, C.C.M. Testing for changes in light emissions from certified International Dark Sky Places. Int. J. Sustain. Light. 2019, 21, 11-19. [CrossRef]

74. Fu, D.; Xia, X.; Duan, M.; Zhang, X.; Li, X.; Wang, J.; Liu, J. Mapping nighttime PM2.5 from VIIRS DNB using a linear mixed-effect model. Atmos. Environ. 2018, 178, 214-222. [CrossRef]

75. Zhang, J.; Jaker, S.L.; Reid, J.S.; Miller, S.D.; Solbrig, J.; Toth, T.D. Characterization and application of artificial light sources for nighttime aerosol optical depth retrievals using the Visible Infrared Imager Radiometer Suite Day/Night Band. Atmos. Meas. Tech. 2019, 12, 3209-3222. [CrossRef]

76. Doll, C.H.; Muller, J.P.; Elvidge, C.D. Night-time Imagery as a Tool for Global Mapping of Socioeconomic Parameters and Greenhouse Gas Emissions. AMBIO A J. Hum. Environ. 2000, 29, 157-162. [CrossRef]

77. Barentine, J.C.; Walker, C.E.; Kocifaj, M.; Kundracik, F.; Juan, A.; Kanemoto, J.; Monrad, C.K. Skyglow changes over Tucson, Arizona, resulting from a municipal LED street lighting conversion. J. Quant. Spectrosc. Radiat. Transf. 2018, 212, 10-23. [CrossRef]

78. Kyba, C.; Ruby, A.; Kuechly, H.; Kinzey, B.; Miller, N.; Sanders, J.; Barentine, J.; Kleinodt, R.; Espey, B. Direct measurement of the contribution of street lighting to satellite observations of nighttime light emissions from urban areas. Light. Res. Technol. 2020, 147715352095846. [CrossRef]

79. Barentine, J.C.; Kundracik, F.; Kocifaj, M.; Sanders, J.C.; Esquerdo, G.A.; Dalton, A.M.; Foott, B.; Grauer, A.; Tucker, S.; Kyba, C.C. Recovering the city street lighting fraction from skyglow measurements in a large-scale municipal dimming experiment. J. Quant. Spectrosc. Radiat. Transf. 2020, 253, 107120. [CrossRef]

80. Bullough, J.D.; Donnell, E.T.; Rea, M.S. To illuminate or not to illuminate: Roadway lighting as it affects traffic safety at intersections. Accid. Anal. Prev. 2013, 53, 65-77. [CrossRef]

81. Wanvik, P.O. Effects of road lighting: An analysis based on Dutch accident statistics 1987-2006. Accid. Anal. Prev. 2009, 41, 123-128. [CrossRef]

82. Morrow, N.; Hutton, S. The Chicago Alley Lighting Project: Final Evaluation Report; Technical Report; Illinois Criminal Justice Information Authority:

Chicago, IL, USA, 2000.

83. Sullivan, J.M.; Flannagan, M.J. The role of ambient light level in fatal crashes: Inferences from daylight saving time transitions. Accid. Anal. Prev. 2002, 34, 487-498. [CrossRef]

84. Marchant, P.R. A Demonstration That the Claim That Brighter Lighting Reduces Crime Is Unfounded. Br. J. Criminol. 2004, 44, 441-447. [CrossRef]

85. Marchant, P. Have new street lighting schemes reduced crime in London? Radic. Stat. 2011, 104, $39-48$.

86. Wanvik, P.O. Effects of Road Lighting on Motorways. Traffic Inj. Prev. 2009, 10, 279-289. [CrossRef] 
87. Steinbach, R.; Perkins, C.; Tompson, L.; Johnson, S.; Armstrong, B.; Green, J.; Grundy, C.; Wilkinson, P.; Edwards, P. The effect of reduced street lighting on road casualties and crime in England and Wales: Controlled interrupted time series analysis. $J$. Epidemiol. Community Health 2015, 69, 1118-1124. [CrossRef]

88. Marchant, P. Why Lighting Claims Might Well Be Wrong. Int. J. Sustain. Light. 2017, 19, 69-74. [CrossRef]

89. Marchant, P. Do brighter, whiter street lights improve road safety? Significance 2019, 16, 8-9. [CrossRef]

90. Walmsley, L.; Hanna, L.; Mouland, J.; Martial, F.; West, A.; Smedley, A.R.; Bechtold, D.A.; Webb, A.R.; Lucas, R.J.; Brown, T.M. Colour As a Signal for Entraining the Mammalian Circadian Clock. PLoS Biol. 2015, 13, e1002127. [CrossRef]

91. Lewy, A.; Wehr, T.; Goodwin, F.; Newsome, D.; Markey, S. Light suppresses melatonin secretion in humans. Science 1980, 210, 1267-1269. [CrossRef]

92. Carrillo-Vico, A.; Guerrero, J.M.; Lardone, P.J.; Reiter, R.J. A Review of the Multiple Actions of Melatonin on the Immune System. Endocrine 2005, 27, 189-200. [CrossRef]

93. Phillips, A.J.K.; Vidafar, P.; Burns, A.C.; McGlashan, E.M.; Anderson, C.; Rajaratnam, S.M.W.; Lockley, S.W.; Cain, S.W. High sensitivity and interindividual variability in the response of the human circadian system to evening light. Proc. Natl. Acad. Sci. USA 2019, 116, 12019-12024. [CrossRef] [PubMed]

94. Durrant, J.; Green, M.P.; Jones, T.M. Dim artificial light at night reduces the cellular immune response of the black field cricket, Teleogryllus commodus. Insect Sci. 2019, 27, 571-582. [CrossRef] [PubMed]

95. Kernbach, M.E.; Hall, R.J.; Burkett-Cadena, N.D.; Unnasch, T.R.; Martin, L.B. Dim light at night: Physiological effects and ecological consequences for infectious disease. Integr. Comp. Biol. 2018, 58, 995-1007. [CrossRef] [PubMed]

96. Falchi, F.; Cinzano, P.; Duriscoe, D.; Kyba, C.C.M.; Elvidge, C.D.; Baugh, K.; Portnov, B.A.; Rybnikova, N.A.; Furgoni, R. The new world atlas of artificial night sky brightness. Sci. Adv. 2016, 2, e1600377. [CrossRef]

97. Falchi, F.; Furgoni, R.; Gallaway, T.; Rybnikova, N.; Portnov, B.; Baugh, K.; Cinzano, P.; Elvidge, C. Light pollution in USA and Europe: The good, the bad and the ugly. J. Environ. Manag. 2019, 248, 109227. [CrossRef]

98. Davis, G. History of the NOAA satellite program. J. Appl. Remote Sens. 2007, 1, 012504. [CrossRef]

99. Elvidge, C.D.; Keith, D.M.; Tuttle, B.T.; Baugh, K.E. Spectral Identification of Lighting Type and Character. Sensors 2010, 10, 3961-3988. [CrossRef]

100. Elvidge, C.D.; Baugh, K.E.; Zhizhin, M.; Hsu, F.C. Why VIIRS data are superior to DMSP for mapping nighttime lights. Proc. Asia Pac. Adv. Netw. 2013, 35, 62. [CrossRef]

101. Cinzano, P.; Falchi, F.; Elvidge, C. The first World Atlas of the artificial night sky brightness. Mon. Not. R. Astron. Soc. 2001, 328, 689-707. [CrossRef]

102. Huang, Q.; Yang, X.; Gao, B.; Yang, Y.; Zhao, Y. Application of DMSP/OLS Nighttime Light Images: A Meta-Analysis and a Systematic Literature Review. Remote Sens. 2014, 6, 6844-6866. [CrossRef]

103. De Miguel, A.S.; Castano, J.G.; Zamorano, J.; Pascual, S.; Angeles, M.; Cayuela, L.; Martinez, G.M.; Challupner, P.; Kyba, C.C.M. Atlas of astronaut photos of Earth at night. Astron. Geophys. 2014, 55, 4.36. [CrossRef]

104. De Miguel, A.S. Variación Espacial, Temporal Y Espectral De La Contaminación Lumínica Y Sus Fuentes: Metodología Y Resultados. Ph.D. Thesis, Universidad Complutense de Madrid, Madrid, Spain, 2015. [CrossRef]

105. De Miguel, A.S.; Kyba, C.C.; Aubé, M.; Zamorano, J.; Cardiel, N.; Tapia, C.; Bennie, J.; Gaston, K.J. Colour remote sensing of the impact of artificial light at night (I): The potential of the International Space Station and other DSLR-based platforms. Remote Sens. Environ. 2019, 224, 92-103. [CrossRef]

106. De Miguel, A.S.; Zamorano, J.; Castaño, J.G. Image Classification of Night Time Images Detected from the International Space Station; Technical Report 24808; Universidad Complutense de Madrid: Madrid, Spain, 2014.

107. Elvidge, C.D.; Cinzano, P.; Pettit, D.R.; Arvesen, J.; Sutton, P.; Small, C.; Nemani, R.; Longcore, T.; Rich, C.; Safran, J.; et al. The Nightsat mission concept. Int. J. Remote Sens. 2007, 28, 2645-2670. [CrossRef]

108. Jiang, W.; He, G.; Long, T.; Guo, H.; Yin, R.; Leng, W.; Liu, H.; Wang, G. Potentiality of Using Luojia 1-01 Nighttime Light Imagery to Investigate Artificial Light Pollution. Sensors 2018, 18, 2900. [CrossRef]

109. Li, X.; Li, X.; Li, D.; He, X.; Jendryke, M. A preliminary investigation of Luojia-1 night-time light imagery. Remote Sens. Lett. 2019, 10, 526-535. [CrossRef]

110. Zheng, Q.; Weng, Q.; Huang, L.; Wang, K.; Deng, J.; Jiang, R.; Ye, Z.; Gan, M. A new source of multi-spectral high spatial resolution night-time light imagery-JL1-3B. Remote Sens. Environ. 2018, 215, 300-312. [CrossRef]

111. Levin, N.; Johansen, K.; Hacker, J.M.; Phinn, S. A new source for high spatial resolution night time images-The EROS-B commercial satellite. Remote Sens. Environ. 2014, 149, 1-12. [CrossRef]

112. Katz, Y.; Levin, N. Quantifying urban light pollution-A comparison between field measurements and EROS-B imagery. Remote Sens. Environ. 2016, 177, 65-77. [CrossRef]

113. Pack, D.; Hardy, B.; Longcore, T. Studying the Earth at Night from CubeSats. In Proceedings of the 31st Annual AIAA/USU Conference on Small Satellites, Logan, UT, USA, 5-10 August 2017; Number 10, p. 41.

114. Bará, S.; Rodríguez-Arós, Á.; Pérez, M.; Tosar, B.; Lima, R.; de Miguel, A.S.; Zamorano, J. Estimating the relative contribution of streetlights, vehicles, and residential lighting to the urban night sky brightness. Light. Res. Technol. 2018, 51, $1092-1107$. [CrossRef]

115. Meier, J.M. Temporal Profiles of Urban Lighting: Proposal for a research design and first results from three sites in Berlin. Int. J. Sustain. Light. 2018, 20, 11. [CrossRef] 
116. Levin, N.; Kyba, C.C.; Zhang, Q.; de Miguel, A.S.; Román, M.O.; Li, X.; Portnov, B.A.; Molthan, A.L.; Jechow, A.; Miller, S.D.; et al. Remote sensing of night lights: A review and an outlook for the future. Remote Sens. Environ. 2020, 237, 111443. [CrossRef]

117. De Meester, J.; Storch, T. Optimized Performance Parameters for Nighttime Multispectral Satellite Imagery to Analyze Lightings in Urban Areas. Sensors 2020, 20, 3313. [CrossRef] [PubMed]

118. De Miguel, A.S.; Aubé, M.; Zamorano, J.; Kocifaj, M.; Roby, J.; Tapia, C. Sky Quality Meter measurements in a colour-changing world. Mon. Not. R. Astron. Soc. 2017, 467, 2966-2979. [CrossRef]

119. Evans, J.; Carter, S.; Freeman, D.; Gorman, M. Dim nighttime illumination alters photoperiodic responses of hamsters through the intergeniculate leaflet and other photic pathways. Neuroscience 2012, 202, 300-308. [CrossRef]

120. Kyba, C.C.M.; Mohar, A.; Posch, T. How bright is moonlight? Astron. Geophys. 2017, 58, 1.31-1.32. [CrossRef]

121. Roach, F.; Gordon, J. The Light of the Night Sky; Geophysics and Astrophysics Monographs; Ridel Publishing Co.: Boston, MA, USA, 1973; Volume 4.

122. Kummu, M.; Varis, O. The world by latitudes: A global analysis of human population, development level and environment across the north-south axis over the past half century. Appl. Geogr. 2011, 31, 495-507. [CrossRef]

123. Tuttle, B.; Anderson, S.; Elvidge, C.; Ghosh, T.; Baugh, K.; Sutton, P. Aladdin's Magic Lamp: Active Target Calibration of the DMSP OLS. Remote Sens. 2014, 6, 12708-12722. [CrossRef]

124. Dalby, S. Framing the Anthropocene: The good, the bad and the ugly. Anthr. Rev. 2015, 3, 33-51. [CrossRef] 